8
9
10Abstract

\title{
Hyperspectral measurements of yellow rust and fusarium head blight in cereal crops: Part 2: On-line field measurement
}

\author{
Rebecca L Whetton ${ }^{\mathrm{a}}$, Toby W Waine ${ }^{\mathrm{a}}$, and Abdul M Mouazen ${ }^{\mathrm{a}, \mathrm{b} *}$
}

${ }^{\mathrm{a} C r a n f i e l d ~ S o i l ~ a n d ~ A g r i F o o d ~ I n s t i t u t e, ~ C r a n f i e l d ~ U n i v e r s i t y, ~ B e d f o r d s h i r e ~ M K 43 ~ 0 A L, ~ U K . ~}$

b Department of Soil Management, Ghent University, Coupure 653, 9000 Gent, Belgium.

1 Yellow rust and fusarium head blight cause significant losses in wheat and barley yields.

Mapping the spatial distribution of these two fungi diseases at high sampling resolution is essential for variable rate fungicide application (in case of yellow rust) and selective harvest (in case of fusarium head blight). This study implemented a hyperspectral line imager (spectrograph) for on-line measurement of these diseases in wheat and barley in four fields in Bedfordshire, the UK. The \% coverage was assessed based on two methods, namely, infield visual assessment (IVA) and photo interpretation assessment (PIA) based on 100-point grid overlaid RGB images. The spectral data and disease assessments were subjected to partial least squares regression (PLSR) analyses with leave-one-out cross-validation. Results showed that both diseases can be measured with similar accuracy, and that the performance is better in wheat, as compared to barley. For fusarium, it was found that PIA analysis was more accurate for on-line measurement than IVA. The prediction accuracy obtained with PIA was classified as good to moderately accurate, since residual prediction deviation (RPD) values were 2.27 for wheat and 1.56 for barley, and $\mathrm{R}^{2}$ values were 0.82 and 0.61 , respectively. 
25 Similar results were obtained for yellow rust but with IVA, where model performance was

26 classified as moderately accurate in barley $\left(\mathrm{RPD}=1.67, \mathrm{R}^{2}=0.72\right)$ and good in wheat (RPD

$\left.27=2.19, \mathrm{R}^{2}=0.78\right)$. It is recommended to adopt the proposed approach to map yellow rust and

28 fusarium head blight in wheat and barley.

29

\section{Keywords}

31 On-line measurement, yellow rust, fusarium head blight, wheat, barley, mapping, partial least squares

32 regression.

\section{Introduction}

35 Site specific fungi disease control is a large task for successful production of cereals worldwide, and

36 requires data sampled at high spatial resolution due to in-field variation of these diseases. The severity

37 of these diseases depends mainly on weather conditions, which necessitates information not only on disease spread, but weather conditions too. Yellow rust (Puccinia. striiformis) is a foliar disease that

39 is common in cool climates, and is one of the most devastating diseases of wheat worldwide, reducing

40 crop yields by up to 7 tonne ha $^{-1}$ in severe epidemics (Ma et al., 2001; Bravo et al., 2003). In 2009

41 yellow rust mutations have enabled the disease to attack several widely grown genetically resistant

42 cereal crop varieties, including Solstice (Milus et al., 2009). Another important fungal disease that

43 attacks cereal crops is fusarium head blight, with the most aggressive and prevalent species (Fusarium

44graminearum ), causing mycotoxins in the grain (Desjardin, 2006; Brennan et al., 2003; Leslie and

45 Summerell, 2006; Rotter et al., 1996). Fusarium predominantly affects the ear of the crop and has

46 become one of the most important pre-harvest diseases worldwide. Like yellow rust, fusarium head

47 blight also causes reduction in yield quantity and quality and when producing mycotoxins it becomes

48 a significant threat to both humans and animals. Fusarium head blight is a sporadic disease, that is 
dependent on warm humid weather conditions (Rossi et al., 2001; Xu, 2003), causing variability of disease presence and level of infection across regions, and years (Jelinek et al., 1989). Both yellow rust and fusarium species can survive in soil and weeds occurring in the hedgerows and borders of a field, and fusarium head blight also survives within plant residues even after 2 years, acting as a source of inoculum (Imathiu et al., 2013; Jenkinson and Parry, 1994; Champeil et al., 2004). Therefore, control of mycotoxins caused by fusarium fungi is required to prevent toxic contamination reaching the food chain either in milling grain (for human consumption) or as cattle feed (Magan et al., 2002).

Traditionally, disease detection is carried out manually by human experts using visual assessments of disease coverage throughout the field, a process that can be lengthy, subjective and tiresome (Schmale and Bergstrom, 2003; Bock et al., 2010). This method is limited in providing high sampling resolution data on spatial variability of crop disease. Therefore, on-line mobile systems are necessary to inform site specific application of fungicides.

It has been stated that optical technologies are available for development into suitable disease detection systems, but with many challengers still required to be overcome (West et al., 2003). Although on-line applications are still rather limited, optical techniques have the potential to be integrated with agricultural vehicles. Optical (both remote and proximal) methods can provide noninvasive, high sampling resolution data that are necessary for monitoring and mapping of crop diseases. Among optical sensing methods, hyperspectral and multispectral imaging techniques are among the best candidates, as they have been used in disease and stress monitoring (Hahn, 2009). Non-mobile (off-line) field and laboratory methods for disease classification and plant growing conditions have been studied and demonstrated (Roggo et al., 2003; Wu et al., 2008). The early success in field studies for hyperspectral image-based detection of yellow rust (Moshou et al., 2004 and Bravo et al., 2003) focused on the presence of yellow rust in the field, not necessarily the severity. Moshou et al., (2005) implemented a data fusion approach of a hyperspectral (450-900 nm) and fluorescence (550-690 $\mathrm{nm}$ ) imaging techniques for yellow rust detection in winter wheat, 
reporting $94.5 \%$ accuracy. Other common attempts with hyperspectral and multispectral imagery are targeted to leaves rather than the canopy (Bock et al., 2010). Huang et al. (2015) successfully provided quantitative assessment of yellow rust in winter wheat, by hyperspectral measurement of individual infected leaves. Zhou et al. (2015) used low cost RGB images for quantification of yellow rust, reporting $74 \%$ and $81 \%$ detection accuracies. Zhao et al. (2016) focused on two sensitive bands (558 nm and $856 \mathrm{~nm}$ ) in the wavelength ranges of 550-680 nm and 750-1300 nm to detect yellow rust with $90.6 \%$ accuracy. Krishna et al. (2014) used remote hyperspectral data in 350 to $2500 \mathrm{~nm}$ range for quantitative identification of yellow rust. To the best of our knowledge there are no reports in the literature on on-line application of proximally captured hyperspectral imagery for simultaneous assessment and mapping of yellow rust and fusarium head blight in wheat and barley. Such analyses in laboratory conditions was discussed in Part 1 of this study (Whetton et al., 2017b), where plants in trays were subjected to variable water stress, and were inoculated with yellow rust and fusarium head blight. The aim of this paper is to implement a hyperspectral imager for on-line measurement of yellow rust and fusarium head blight in wheat and barley grown commercially outdoors in the fields.

\section{2. Materials and methods}

\subsection{Field sites}

91 Field measurements were conducted in four different field sites through the 2015 cropping season. These sites were located at Duck End farm, Wilstead, Bedfordshire, UK (5205'46.3"N 0²6'41.4"W), with an average annual rainfall of $598 \mathrm{~mm}$. The farm has a three year crop rotation of oil seed rape, winter wheat and winter barley. Fields varied in size between 12, 10, 7 and 4 ha (Table 1), to allow for pattern identification of diseases with different field size. This is because yellow rust and fusarium head blight occurrence in the field often begins nearer the hedgerows, and the spread pattern throughout the growing season may well depend on the shape and size of the field. Winter wheat was grown in three fields, whereas winter barley was grown in the 10 ha field only. The largest and smallest winter wheat fields were scanned at two different intervals. Timing and growth stage of measurement in each field is shown in Table 1. Growth stage in this study refers to the Zadok's scale 
101 (Zadoks et al., 1974). The dominant soil texture types in the fields are shown in Table 1, with sand

102 fractions due to underlying gravel deposits.

103

104

105

106

107

108

109

110

111

112

113

114

115

116

117

118

119

120

121

122

123

124

125

126

\subsection{Soil moisture content measurement}

An on-line visible and near infrared (vis-NIR) spectroscopy soil sensor developed by Mouazen (2006) was used in this study to measure gravimetric soil moisture content (MC) in field 4, with the objective of studying the influence of MC on crop disease spatial distribution. The system consists of a subsoiler, opening a smooth trench at $15 \mathrm{~cm}$ depth (Mouazen et al., 2005). The sensor was mounted on a three-point linkage of a tractor travelling at a speed of $3 \mathrm{~km} \mathrm{~h}^{-1}$ and collecting soil spectral data at $10 \mathrm{~m}$ parallel intervals. In order to measure soil spectra an AgroSpec mobile, fibre type, vis-NIR spectrophotometer (Tec5 Technology for Spectroscopy, Oberursel, Germany), with a measurement range of $305-2200 \mathrm{~nm}$ and a light source of $20 \mathrm{~W}$ tungsten halogen lamp were used (Kuang \& Mouazen, 2013). A DGPS (EZ-Guide 250, Trimble, California, USA) recorded the position of the online spectra with sub-meter accuracy. The collection of soil spectra and DGPS readings took place at 1 sec sampling resolution using AgroSpec software (Tec5 Technology for Spectroscopy, Oberursel, Germany). A previously developed MC PLSR model (Halcro et al., 2013) was used to predict MC based on on-line collected spectra in the field.

\subsection{Hyperspectral on-line data capture}

In this study the term 'on-line' refers to a mobile measurement system, attached to a moving platform (e.g., a tractor), where spectral data is captured whilst the platform is in motion, whereas 'non-mobile' is defined as capturing the hyperspectral data in a stationary position. A push broom hyperspectral imager (spectrograph) (HS spectral camera model from Gilden Photonics Ltd., UK) and light source were mounted on a tractor by means of a metal frame (Figure 1). Optimal hyperspectral measurement configurations set by Whetton et al. (2017a) were considered in the design and manufacturing of this on-line measurement system of crop canopy. These include an integration time of $50 \mathrm{~ms}$, a camera height of $0.3 \mathrm{~m}$ and light height and distance of $1.2 \mathrm{~m}$ and a camera angle of $10^{\circ}$. The on-line measurements were carried out at a travel speed of approximately $4 \mathrm{~km} \mathrm{~h}^{-1}$. Sampling resolution was 1 
$\mathrm{Hz}$, which is subsequently logged and geo-located with sub-meter accuracy, using a differential global positioning system (DGPS) (EZ-Guide 250, Trimble, California, USA). The direction and angle of the imager was kept consistent, and a day with uniformly overcast weather was selected, which helped prevent issues of moving shadows from lateral sun movement on the data (West et al., 2003).

The same hyperspectral imager used in Part 1 of this study was used for on-line field measurement, along with two external halogen lamps. It consists of 1608 pixels, with a spectral range of $400-1000$ nm. More details about the hyperspectral imager's properties can be found in Whetton et al. (2017a). In order to compile a full image from a set of line imagery, a steady moving platform is needed to sweep across the target object to capture every line (Gilden Photonics Ltd, Glasgow, UK). However, due to practical constraints of applying a consistent moving platform, the spectraSENS v3.3 software

137 (Gilden Photonics Ltd, Glasgow, UK) was adapted to record a single line array. Before data capture, a 138 white and dark reference were collected, and subsequently repeated at 10 minute intervals until the scanning was completed. The white reference used was a commercially available Spectralon Teflon white reflectance panel with $99.9 \%$ reflectance value. The collected on-line data was corrected by the

141 white and dark scans after data collection was complete, providing the relative reflectance.

\section{2.4. Disease recognition in the field}

143 During field scans with the hyperspectral imager, ground truth locations were selected randomly, at a 144 rate of five samples per hectare (Figure 2), and a set of five hyperspectral images were collected per 145 ground truth location, covering $1 \mathrm{~m}^{2}$ plot. The measurement position was recorded with a DGPS. The 146 disease assessment was assigned to each of the five scans. In order to assist in disease and crop health 147assessments , a photograph was collected at each position using an RGB, 5 megapixel camera with a $148 \quad 3.85 \mathrm{~mm} \mathrm{f} / 2.8$ lens at the same time of hyperspectral image capture. The $1 \mathrm{~m}^{2}$ ground truth locations 149 were used for disease recognition. A block diagram illustrating the different steps followed for 150 diseases quantification and mapping is shown in Figure (3).

151 Disease assessment was based on the following two methods: 
1- Photo interpretation assessment (PIA): RGB photos collected from the ground truth plots were used

153 in this analysis to assess crop disease coverage and incidence, defined by Chiarappa (1981) as the

154 percentage cover of disease, and the number of individual infected plants in ratio to the healthy individuals, respectively. Images were overlaid with a 100-point grid at equal spacing as illustrated in Figure (4), adopting a similar approach to that proposed by Knight et al., (2006). At the centre of each point, the object and health status were recorded and used to calculate the percent coverage of infection, or incidence of disease, an example is given in Table 2. This approach was adopted for both the yellow rust and fusarium assessment.

2- Infield visual assessment (IVA): Although visual assessment of crop diseases deemed to be subjective, it is the most common and adopted by partitions. IVA of both diseases at the ground truth plots were made at four levels, namely, the head (when present), at the flag leaves, at $2^{\text {nd }}$ and $3^{\text {rd }}$ leaves (mid canopy), and at the lower canopy. This was done in the field, at the time of the on-line scanning. Details on this method can be found in Part 1 of this study (Whetton et al., 2017b). The assessment for fusarium head blight considered both early and later symptoms on heads, and were assessed as a percent of occurrence of infected ears. For yellow rust, quantitative assessments were recorded, for the percent of disease cover on the leaves.

\subsection{Data analyses}

\subsubsection{Crop canopy spectral data pre-processing}

The first step of spectra pre-processing included removing noisy wavelengths smaller than $400 \mathrm{~nm}$ and larger than $750 \mathrm{~nm}$. Following the suggestion made in Whetton et al., (2017a), the first and last 320 pixels were removed from each line scan. Noise removal was followed successively by reducing

173 the number of variables by averaging three neighbouring wavelengths, maximum normalisation, first

174 derivative and smoothing. All spectra pre-processing was carried out using Unscrambler 10 software 175 (Camo Inc.; Oslo, Norway). Although pre-processing of spectral data includes techniques such as smoothing, if the process of cleaning the data is intensive due to noisy spectra it can lead to the loss of important spectral features, and thus impact on the success of analysis (Dasu \& Johnson, 2003). 
178 Therefore, a gentle smoothing of 2:2 was implemented during the first derivative and smoothing using

179 Savitzky-Golay algorithm. Detailed information about the spectra pre-processing steps can be found 180 in Martens \& Naes (1989).

\subsubsection{Calibration models for prediction of yellow rust and fusarium head blight diseases}

182 For yellow rust analysis, the data from the five scans from the three wheat fields (Table 1) and the one scan from the barley field were considered. However, for fusarium head blight the late captured data of each field was used. This is because fusarium head blight occurs at a late crop growth stage, when the ear emerges (51), and potential infection can occur when the crop is booting (43) by washing into the sheath (Anand et al., 2003).

Before running the PLSR analysis, the yellow rust dataset was divided into calibration (80\%, e.g., 940 samples), non-mobile (spectra are captured at stationary state) validation (25\%, e.g., 235 samples) and on-line (spectra are captured on the move) validation (20\%, e.g., 235 samples) sets. However, since at each ground truth location 5 scans were collected, from which an average scan per location was calculated. The final number of samples is reduced to 188 in the calibration set and 47 in each of the non-mobile and on-line validation sets. Similar partitioning of samples was carried out for fusarium samples, although smaller numbers of samples were available $(124,31$ and 31 for calibration, nonmobile validation and on-line validation, respectively). Statistical overview of samples used for PLSR analyses for the assessment of yellow rust and fusarium head blight is shown in Table 3 and Table 4, respectively, whereas statistics overview of samples used for on-line validation of PLSR models in barley is shown in Table 5 .

The pre-processed canopy spectral data was augmented with the estimated fungal diseases based on PIA and IVA in one matrix. PLSR analyses with leave-one-out cross-validation was carried out on the calibration datasets (75\% of samples) using Unscrambler 10 software (Camo Inc.; Oslo, Norway). PLSR. The input variables to PLSR were wavelengths $(400-750 \mathrm{~nm})$ and disease assessed as \% coverage, and the following four PLSR analyses were carried out: 
1. Yellow rust based on IVA.

2. Yellow rust based on photo interpretation.

3. Fusarium head blight based on IVA.

4. Fusarium head blight based on photo interpretation.

207 Outliers were detected, and removed to a maximum of $5 \%$ of the total data. The wheat data was used to establish the PLSR calibration models, and underwent both cross-validation and independent validations (both non-mobile and on-line). No barley data was considered in the cross-validation, so 210 that on-line disease predictions were carried out using the PLSR calibration models for wheat (Table

211 5). The performance of PLSR models were validated using the remaining $25 \%$ samples, which were 212 not considered in the cross-validation stage. Validation was done using non-mobile collected spectra 213 and the on-line collected data in the field by the mounted hyperspectral imager. For the on-line validation, predicted and assessed values were overlaid at the same or a very close position. However, the position of the on-line data did not always perfectly align to the ground truth spot position, due to

216 the capture rate of the hyperspectral imager, and the accuracy of the DPGS system. Therefore, for 217 validating the on-line predictions, a scanned area of $5 \mathrm{~m}^{2}$ was considered, and the ground truth spot 218 was located in the middle. This meant that for some ground truth points there were up to 3 on-line 219 predicted values; the greatest match between measurement and prediction was used. This was done with ArcGIS 10 software (ESRI, California, USA).

221 The PLSR model performance was evaluated in cross-validation, non-mobile validation and on-line validation by means of $\mathrm{R}^{2}$, root mean square error of prediction (RMSEP) and residual prediction deviation (RPD), which is the standard deviation of observations divided by RMSEP. In order to compare the performances of the different developed models we used a metric proposed by Whetton et al., (2017b) for crop disease analysis. Details of different prediction performance categories are provided in Table 6. 


\subsubsection{Mapping of yellow rust and fusarium head blight diseases}

228 Maps for the on-line predicted yellow rust and fusarium head blight were developed with ArcGIS 10

229 software (ESRI, California, USA). Kriging was used to develop maps from the data collected from the 230 tramlines illustrated in Figure (2), assuming that the distance or direction between sample points 231 reflects a spatial correlation that can be used to explain spatial variations. To distinguish these spatial 232 variations, semi-variograms were developed in Rstudio (RStudio, Boston, MA) and then applied to 233 the kriging by utilising the advanced parameters option in ArcGIS 10 software (ESRI, California, 234USA).

\section{3. Results and Discussion}

\section{3.1. Crop canopy spectra analysis}

238

239 Typical crop canopy spectra were recorded in the field for wheat (Figure 5) and barley 240 (Figure 6), with similar spectral features to those reported by Whetton et al., (2017b) under

241 laboratory scanning conditions. However, the squared difference of $650 \& 700(\mathrm{~nm})$ in field 242 spectra is much larger than that in the laboratory spectra, which may indicate larger 243 absorption in the 400-650 $\mathrm{nm}$ range by the darker canopy colour associated with larger 244 intensity of chlorophyll in leaves. This large absorption (small reflectance) masks the 245 significant band at $670 \mathrm{~nm}$, associated with red colour band at $680 \mathrm{~nm}$ and linked to 246chlorophyll a (Hunt et al., 2013).

247 Zhang and Zhang (2016) recommend the use of the spectral range of 470 to $800 \mathrm{~nm}$ sensitive 248 to chlorophyll, to monitor crop diseases. Larger absorption (smaller relative reflectance) can 249 be observed for a late stage captured spectra, as compared to early stage, which may be 250 attributed to the increase of crop density and leaf area through the cropping season. 
251 Furthermore, both on-line and non-mobile spectra captured late in the growing season were mobile condition.

Similarly, on-line and non-mobile spectra of barley canopy collected at anthesis growth stage show large similarity. Only slight differences in reflection can be observed at $520-550 \mathrm{~nm}$ and at $670-$ $750 \mathrm{~nm}$ spectral ranges. Again the high similarity between the on-line and non-mobile spectra is a good indication of the hyperspectral system stability in providing high quality spectra to enable modelling yellow rust and fusarium head blight with desirable accuracy, to be evaluated in the following section.

\subsection{Evaluation of model performance}

262 Based on $\mathrm{R}^{2}$ values in cross-validation (Table 7), it could be suggested that the performance of the 263 wheat models is better for fusarium than for yellow rust predictions. The independent validation based on non-mobile collected spectra in the field indicates a similar trend to cross-validation (Table 7), where estimation of $\%$ coverage of yellow rust (RPD $=1.3$ and 2.14 for PIA and IVA, respectively) is slightly less successful than for fusarium head blight (RPD $=1.4$ and 2.31 for IVA and PIA, respectively). The PIA is worth performing for yellow rust prediction $(\mathrm{RPD}=1.3)$, compared to IVA $(\mathrm{RPD}=2.14)$, whereas the opposite is true for fusarium head blight $(\mathrm{RPD}=2.31$ for PIA and 1.4 for IVA). Therefore, the best non-mobile prediction performance of yellow rust obtained with IVA (RPD $=2.14)$ can be classified as a good prediction performance, whereas the best prediction performance

271 for fusarium head blight obtained with PIA (RPD = 2.31) can also be classified as good prediction ability (Table 8). The implication of this result is that IVA should be adopted for yellow rust, and PIA for fusarium head blight under non-mobile measurement conditions.

274 It should discussed why IVA is better performing for yellow rust detection, while PIA for fusarium

275 head blight. The reason is that the former consider infection of all parts on the canopy, while the 
276 former based on RGB image might not capture yellow rust in the low canopy layers. This is the 277 reason why Zhao et al. (2016) recommended investigating the disease development for different leaf 278 layers. Fusarium head blight seems to be better captured in the RGB image than yellow rust as the 279 disease appears on heads that present at the top of the crop canopy; hence, fusarium disease is 280 unlikely to be obscured like yellow rust, allowing for an accurate count and representation to be made 281 with the PIA. The PIA also removes the potential of subjectivity between assessments. Due to yellow rust being a foliar disease and there being overlapping in a canopy, the level of disease could be

283 hidden in an RGB image. Whilst it's arguable that the RGB photograph would be representing the 284 same area seen by the hyperspectral imager, the latter may pick up alterations in the crop's reflectance 285 due to yellow rust, which can be captured by the spectral data.

286Huang et al. (2015) successfully assessed yellow rust in winter wheat, reporting a high $\mathrm{R}^{2}$ value of 2870.88 , based on hyperspectral measurements of individual infected leaves, which is of limited use as 288 compared to canopy measurement adopted in the current work. Peteinatos et al. (2016) measured spectral reflectance using two hand-held passive spectrometers and one fluorometer, and concluded that early detection of yellow rust was possible. Adopting a data fusion approach of hyperspectral data 291 (450 - $900 \mathrm{~nm})$ and fluorescence data $(550-690 \mathrm{~nm})$, Moshou et al. (2005), reported a high accuracy $292(94.5 \%)$ of detection for yellow rust in winter wheat. They needed two detection techniques to 293 achieve this accuracy, which makes the approach adopted rather expensive and complicated to use in 294 the field. Similar reliable results for quantitative identification of yellow rust in winter wheat have been demonstrated by Krishna et al., (2014), achieving high $\mathrm{R}^{2}$ and RPD values of 0.90 of 3.8 , respectively. However, they have to include the entire visible and near infrared range (e.g., visible and near infrared (VNIR) and short wavelength infrared (SWIR) of 350 to $2500 \mathrm{~nm}$ ) to reach this accuracy, whereas the current work achieved good $(\mathrm{RPD}=2.14)$ prediction accuracy, based on a relatively cost-effective hyperspectral camera, in the visible range only.

300 There is limited literature for fusarium head blight detection in the field, which may be attributed to 301 the difficult detection of symptoms appearing on ears. Polder et al.,(2005) reported successful 
detection of fusarium head blight in single kernels, by using both spectroscopy and imaging.

303 Similarly, Delwiche and Kim (2000) successfully used a hyperspectral imager at $435-860 \mathrm{~nm}$ and

304 machine learning for fusarium head blight detection in wheat kernels. Bauriegel (2011) utilised a

305 hyperspectral imager, based on wavelength range intervals of 500-533 nm (green), 560-675 nm

306 (yellow), 682-733 nm (red) and 927-931 nm (red edge), to identify the percent coverage of fusarium

307 disease in ears, achieving average recognition accuracy of $67 \%$ and as high as $87 \%$. Oerke and

308 Steiner (2010) utilised an infrared thermography for in situ detection of fusarium symptoms at a

309 canopy level, by detecting a significantly higher temperature in infected ears.

310 The non-mobile independent validation result for fusarium head blight in wheat (Table 7) is slightly

311 better $\left(\mathrm{R}^{2}=0.85, \mathrm{RMSEP}=0.39 \%\right.$ and $\left.\mathrm{RPD}=2.31\right)$ than that of the on-line validation $\left(\mathrm{R}^{2}=0.82\right.$,

312 RMSEP $=0.63 \%$ and RPD $=2.27)($ Table 8$)$. This is expected as during on-line measurement

313 uncontrollable external conditions such as vibrations and variations in camera and light source heights

314 and angles negatively affect the measurement accuracy. However this is not the case for yellow rust in

315 wheat where a slightly (negligible) better prediction result is observed for the on-line measurement

$316\left(\mathrm{R}^{2}=0.78, \mathrm{RMSEP}=6.13 \%\right.$ and $\left.\mathrm{RPD}=2.19\right)$ compared to the non-mobile measurement $\left(\mathrm{R}^{2}=0.78\right.$,

317 RMSEP $=8.2 \%$ and RPD $=2.14$ ). Results also show that the prediction of fusarium infection in wheat

318 (Table 8) is more accurate than in the barley, which can mainly be attributed to the fact that no

319 spectral data from barely were used in the cross-validation and that the PLSR prediction models

320 developed with wheat spectra only were used to predict these diseases in barely. Other reason might

321 be that wheat data being collected at a later growth stage (e.g., at Milk (70) in field 1 and 2 and at anthesis (61) in field 4) than that for barley (anthesis (61), as shown in Table 1). Since fusarium head

323 blight infects the ear as opposed to the foliage, the impact of fusarium symptoms on spectra in less

324 pronounced in early growing stages (Rossi et al., 2001; Xu, 2003). Indeed, fusarium models are only applicable to late growing stages, when the ears have emerged.

326 For both non-mobile and on-line validations scenarios, yellow rust PLSR prediction models based on 327 IVA outperform the corresponding fusarium models (Table 7 and Table 8), whereas PIA is more 
accurate for fusarium prediction. The PIA provides very poor on-line predictions of yellow rust, as compared to those for fusarium in both barley and wheat fields. The IVA-based PLSR model accuracy for on-line yellow rust prediction can be classified as good for wheat $(\mathrm{RPD}=2.19$, falling in the category of $2-2.5$ (Table 6) and as moderate for barley (RPD $=1.67$ falling in the category of 1.5 - 2 (Table 6). The on-line prediction performance obtained with IVA-PLSR analysis of fusarium is very poor (RPD $=0.47$ and 0.75 for barley and wheat respectively). However, much better on-line predictions of fusarium head blight is obtained with PIA, where the prediction accuracy is classified as good for wheat (RPD $=2.27$, falling in the category of $2-2.5$ (Table 6) and moderate for barely $(\mathrm{RPD}=1.56$, falling the category of $1.5-2$ (Table 6). This results suggest that fusarium head blight should be detected by PIA-PLSR models, whereas yellow rust by the IVA. This is true for both wheat and barley. Similar to the non-mobile predictions, the on-line predictions in wheat were better than those in the barley field, which is expected as models were created using data from wheat fields and then applied to predict disease presence in the barley field to test robustness. Scatter plots of on-line predicted versus reference assessed yellow rust and fusarium head blight are shown in Figure (7).

\subsection{Maps of yellow rust and fusarium head blight diseases}

343 It is essential to explore the spatial variation of these crop diseases at high sampling resolution, which

344 is necessary for variable rate fungicide application (in case of yellow rust) or selective harvest (in case 345 of fusarium head blight). Furthermore, high sampling resolution data/maps can be combined with 346 weather data and incorporated into weather driven disease models to predict the potential spreading 347 pattern and enable early variable rate spraying even before the disease becomes visual.

348 The best models (e.g., PIA for fusarium head blight and IVA analysis for yellow rust) were selected and used to develop corresponding maps in Figures (8) and (9), respectively. The best fit of the spatial data for both disease in all fields are obtained with spherical semi-variograms, whose parameters are shown in Table 9.

352 Examining the spatial distribution of fusarium head blight in the four studied fields, one can easily observe that higher disease coverage appears at the edges, particularly for large area fields (e.g., fields 
3542,3 and 4, shown in Figure (8). Similarly, in the first scans of yellow rust at early growing stage

355 (Figure (9), high infection along the edges of the fields 1 and 3 is also recorded (no measurement was

356 done for fields 2 and 4 due to a technical problem). It can be observed that fusarium spatial

357 distribution in field 1 is significantly different than yellow rust, where high levels appear within the

358 middle part of the field for fusarium (Figure 8) and field edges for yellow rust for both scanning

359 occasions (Figure 9). The field edge pattern can be explained by the fact that both yellow rust and

360 fusarium species can survive in soil and weeds occurring in the hedgerows and borders of a field,

361 acting as a source of inoculum for the following cropping season (Imathiu et al., 2013; Jenkinson and

362 Parry, 1994; Champeil et al., 2004). Initial infections of soil-borne pathogens, commonly result from

363 infected plant residues left over from the previous year's harvest. Fusarium head blight fungi survive

364 over winter on plant tissues and residues as mycelium (Sutton, 1982) and infected residues can

365 produce ascospores and can infect the flag shoot (Oberti et al., 2014), even after two years on the soil

surface (Pereyra et al., 2004).

It is important to point out here that the 7 ha sized field 4 (Figures. 9 \& 10) can be split into two parts.

368 This is in line with the different soil texture types observed for each part, with the north eastern (NE)

369 half being of a heavier soil (clay loam), whilst the other southern west (SW) half being of a lighter

370 soil (sandy clay loam). This split is also reflected on the moisture content map (Figure 10), where the

371 average moisture content of side $\mathrm{A}$ is around $25 \%$ and side $\mathrm{B}$ is around $30 \%$. It's important to

372 mention that the water content levels will vary in a short time period, but due to abiotic factors such as

373 soil texture, elevation and soil depth the distribution pattern of high and low areas will remain steady.

374 This field 4 was only scanned in one occasion at the milk (grain filling) stage on $1^{\text {st }}$ July, 2015, which

375 is quite late in the season. The largest yellow rust infection can be observed on the SW part of the

376 field (Figure 9), whereas fusarium spatial distribution follows an opposite trend, where the highest

377 infection is observed on NE part of the field (Figure 8). Due to the dry but warm conditions of 2015

378 spring, fusarium infection was low in general. It is of particular interest to mention that May

379 according to the UK metrological office was particularly dry, and record breaking temperatures have 
been reached later on in the season. This resulted in half of the field being under substantially more water stress (SW) than the other wetter half (NE), due to the difference in the soil texture type and its ability to retain soil moisture. Subsequently, this soil texture type and moisture retention differences between the two halves affect the crop canopy, and substantially impact the microclimate conditions of the crop. It was reported that a variation in soil texture can lead to variations in soil properties (Silver et al., 2000). For example, an increase in nitrogen will increase the duration and green area index of the canopy, which further affects the microclimate conditions (Stokes et al., 1997; SylvesterBradley and Kindred, 2009). The underlying spatial distribution of moisture content in field 4 (Figure 10) confirms the NE part to have a larger moisture content than the SW part. This comes as a result of plants in the former part having denser, thicker and greener canopy (Part B in Figure 10), than plants in the dryer SW part (Part A in Figure 10). Whilst moisture content will vary quickly, the underlying spatial distribution pattern of water presence will remain similar through the season (Vachaud et al., 1985). Local climate and weather conditions are considered the most influential factor regarding the distribution and severity of fungal infections in a crop stand. Under clear weather conditions in spring and summer, areas of the field with a lower crop density will warm up and cool down faster than those with dense canopies. Temperature in a wheat field's microclimate could have an inter-canopy variation of up to $7.5^{\circ} \mathrm{C}$ (Dammer, 2003), depending on crop canopy density and soil moisture content. Therefore, different soil texture type and subsequently moisture content encountered in this study have affected crop canopy density and humidity and crop health under the exceptional dry conditions in the spring of 2015, which led to the different disease spread pattern in among the two parts of the Field 4.

401 Literature demonstrates that epidemics of fungal diseases are strongly influenced by the local 402 environment, persistence and adaption of the pathogen and the crops variety and physiological condition (Dammer, 2003). Therefore, variation in one of more of these will possibly affect disease distribution, which we believe to be the case in the 7 ha, field 4 . Fusarium head blight is a sporadic disease, which is dependent on warm humid weather conditions, causing variability of disease 
presence (Rossi et al., 2001; Xu, 2003; Jelinek et al., 1989). Furthermore, fusarium head blight is

407 primarily spread by water droplets (Broscious et al., 1985; Sentelhas et al., 1993). The requirement

408 for high humidity for fusarium head blight spread may explain why the NE part of field 4 is of higher

409 fusarium infection ranges than the dryer SW part. In the NE part the crop canopy is denser due to

410 heavier texture and larger MC which results in a higher humidity. However, the higher infection with

411 yellow rust in the dryer SW part of this field can be attributed to the fact that yellow rust spores are

412 predominantly dispersed by wind but require damp from rain or high humid conditions to infect the

413 crops leaves. The less dens canopy of the SW part, as compared to the NE part (Figure 10) allows for

414 better penetration of yellow rust spores by wind, hence increase infection rates in this part. This is an

415 interesting point to consider in plant protection against yellow rust and fusarium head blight, although

416 further investigations are necessary.

417 Due to the absence of high sampling resolution data on crop disease, the current farming practice is to 418 apply fungicide homogeneously, where low infected zones in the field are under dosed and highly 419 infected zones are overdosed. When data becomes available on the spatial distribution of these diseases, variable rate fungicides can be applied using advanced variable rate technologies, and this is

421 expected to result in reducing the amount of fungicide applied and the associated environmental 422 impacts. Examining the spatial distribution of the on-line predicted fusarium head blight (Figure 8) and yellow rust (Figure 9) maps, one can observe the high infection concentrated at the hedgerows and borders of fields. This suggests the need for site specific application of fungicides that should target these highly infected edge parts, and that application should take place at earlier growing stages. This will prevent or at least reduce the possibility of diseases to expand towards the inner parts

427 of fields. Further work will need to use these maps for site specific fungicide applications, followed 428 by cost-benefit and life cycle analysis to evaluate the economic and environmental benefits as compared to the traditional homogeneous applications adopted by majority of farmers today.

430 Developments into the use of hyperspectral imaging at field scale could be further investigated into 431 the use of unmanned aerial vehicles (UAVs), which would remove some limitations of ground 
432 agricultural vehicles related to potential soil compaction, crop damage and low field-coverage 433 efficiency.

\section{Conclusions}

435 This study explored the potential of a hyperspectral line imager $(400-750 \mathrm{~nm})$ for the on-line 436 measurement and mapping of yellow rust and fusarium head blight in wheat and barley, to enable 437 exploring the spatial variation of these crop diseases at high sampling resolution, which is necessary 438 for variable rate fungicide application (in case of yellow rust) or selective harvest (in case of 439 fusarium). The experiment was carried out in four fields, of which one field was cultivated with 440 barley.

441 Yellow rust is more accurately measured using partial least squares regression (PLSR) prediction 442 models developed with the traditional infield visual assessment (IVA) (RPD $=2.19$, a performance 443 classified as a good prediction capability in wheat and moderate prediction capability $(\mathrm{RPD}=1.67)$ in 444 barley. This is because IVA can capture yellow rust spots on low leaves, while the RGB photos 445 considered for the photo interpretation assessment (PIA) fails to a given extent to do so. On the 446 contrary, Fusarium on-line measurement was best performed based on PIA-PLSR models, where the 447 accuracy was classified as good in wheat $(\mathrm{RPD}=2.27)$ and moderate in barley $(\mathrm{RPD}=1.56)$. This is

448 believed to be due to fusarium symptoms appearing on ears, which can be satisfactorily captured by 449 RGB images, than yellow rust attacking the foliage. Results achieved in this study showed that PLSR models developed for fusarium head blight and yellow rust in wheat, can be successfully applied to 451 predict these diseases in barley with some reduction in accuracy.

452 The on-line developed maps confirmed the highest disease coverage to be at the field edges, which 453 was attributed to the fact that these fungi diseases can survive in soil and weeds occurring in the 454 hedgerows and borders of a field, acting as a source of inoculum for the following cropping season. 455 The on-line disease map for one field, when compared to the moisture content map of the same field, revealed that soil texture and moisture content have considerable effect on disease spatial distribution, 
due to their effect on canopy density and subsequently humidity, which in turn affect fusarium head

458 blight and yellow rust spatial pattern.

459 Further work is needed to evaluate the applicability of on-line maps of yellow rust for site specific 460 recommendations of fungicides and of fusarium head blight for selective harvest recommendations, as 461 the late in the cropping season measurement of fusarium head blight may not be useful for variable rate fungicide applications.

\section{Acknowledgement}

464

465

466

467

468

469

470

471

472

473

474

475

476

477

478

479

480

481

482

483

484

485

We acknowledge the funding received for FarmFUSE project from the ICT-AGRI under the European Commission's ERA-NET scheme under the 7th Framework Programme, and the UK Department of Environment, Food and Rural Affairs (contract no: IF0208). The corresponding author acknowledges the FWO funded Odysseus SiTeMan Project (Nr. G0F9216N).

\section{References}

Anand, A., Zhou, T., Trick, H.N., Gill, B.S., Bockus, W.W. and Muthukrishnan, S. (2003). Greenhouse and field testing of transgenic wheat plants stably expressing genes for thaumatin-like protein, chitinase and glucanase against Fusarium graminearum. Journal of Experimental Botany, 54(384), pp.1101-1111.

Bauriegel, E., Giebel, A., Geyer, M., Schmidt, U. and Herppich, W.B. (2011). Early detection of Fusarium infection in wheat using hyper-spectral imaging.Computers and Electronics in Agriculture, 75(2), pp. 304-312.

Bock, C.H., Poole, G.H., Parker, P.E. and Gottwald, T.R. (2010). Plant disease severity estimated visually, by digital photography and image analysis, and by hyperspectral imaging. Critical Reviews in Plant Sciences, 29(2), pp. 59-107

Bravo, C., Moshou, D., West, J., McCartney, A., \& Ramon, H. (2003). Early disease detection in wheat fields using spectral reflectance. Biosystems Engineering, 84(2), pp. 137-145.

Bravo, C., Moshou, D., West, J., McCartney, A. and Ramon, H., 2003. Early disease detection in wheat fields using spectral reflectance. Biosystems Engineering, 84(2), pp.137-145

Brennan, J.M., Egan, D., Cooke, B.M, Doohan, F.M. (2005). Effect of temperature on head blight of wheat caused by Fusarium culmorum and F. graminearum. Plant Pathology, 54, 156. 
Broscious, S.C., Frank, J.A., \& Frederick, J.R. (1985). Influence of winter wheat management practices on the severity of powdery mildew and Septoria blotch in Pennsylvania. Phytopathology, pp. 48875 , pp. 538-542.

489 Champeil, A., Dore, T. and Fourbet, J.F. (2004). Fusarium head blight: epidemiological origin of the effects of cultural practices on head blight attacks and the production of mycotoxins by Fusarium in wheat grains. Plant science, 166(6), pp. 1389-1415.

492 Chiarappa L., ed. (1981). Crop Loss Assessment Methods - Supplement 3. Wallingford; CAB 493 International.

494 Dammer, K.-H. (2003). In: Investigations into the dynamic of climatic parameters and infections with fungi diseases in heterogeneous cereal stands (p. 23). Potsdam, Germany: Jahresbericht des ATB.

496 Dasu, T., \& Johnson, T. (2003). Exploratory data mining and data cleaning (Vol. 479). John Wiley \& 497 Sons.

498 Delwiche, S.R. and Kim, M.S., 2000, December. Hyperspectral imaging for detection of scab in wheat. In Environmental and Industrial Sensing (pp. 13-20). International Society for Optics and 500 Photonics

501 Desjardin, A.E. (2006). Fusarium mycotoxins. Chemistry, Genetics, and Biology. APS Press, St. Paul, 502 MN.

503 Gómez-Casero, M.T., Castillejo-González, I., García-Ferrer, A., Peña-Barragán, J.M., Jurado504 Expósito, M., García-Torres, L. and López-Granados, F. (2010). Spectral discrimination of wild oat 505 and canary grass in wheat fields for less herbicide application. Agronomy for Sustainable 506 Development, 30(3), pp. 689-699.

507 Hahn, F., (2009). Actual pathogen detection: Sensors and algorithms - a review. Algorithms 2, 301508338.

509 Huang, L.S., Ju, S.C., Zhao, J.L., Zhang, D.Y., Teng, L. and Yang, F. (2015). Hyperspectral 510 Measurements for Estimating Vertical Infection of Yellow Rust on Winter Wheat Plant. International 511 Journal of Agriculture \& Biology, 17(6), pp. 1234-1241.

512 Hunt, E.R., Doraiswamy, P.C., McMurtrey, J.E., Daughtry, C.S., Perry, E.M. and Akhmedov, B., 513 2013. A visible band index for remote sensing leaf chlorophyll content at the canopy 514 scale. International Journal of Applied Earth Observation and Geoinformation, 21, pp.103-112

515 Imathiu, S.M., Edwards, S.G., Ray, R.V. and Back, M.A. (2013). Fusarium langsethiae-a HT-2 and 516 T-2 Toxins Producer that Needs More Attention. Journal of Phytopathology, 161(1), pp.1-10

517 Jelinek CF, Pohland AE, Wood GE. (1989) Worldwide occurrence of mycotoxins in foods and feeds518 An update. J AOAC Int, 72, pp. 223-230.

519 Jenkinson, P. and Parry, D.W. (1994). Splash dispersal of conidia of Fusarium culmorum and 520 Fusarium avenaceum. Mycological Research, 98(5), pp.506-510.

521 Knight, J.F., Lunetta, R.S., Ediriwickrema, J. and Khorram, S. (2006). Regional scale land cover 522 characterization using MODIS-NDVI $250 \mathrm{~m}$ multi-temporal imagery: A phenology-based 523 approach. GIScience \& Remote Sensing, 43(1), pp.1-23. 
524 Krishna, G., Sahoo, R.N., Pargal, S., Gupta, V.K., Sinha, P., Bhagat, S., Saharan, M.S., Singh, R. and

525 Chattopadhyay, C., 2014. Assessing wheat yellow rust disease through hyperspectral remote

526 sensing. The International Archives of Photogrammetry, Remote Sensing and Spatial Information

527 Sciences, 40(8), p. 1413.

528 Kuang, B. \& Mouazen, A.M., (2013). Non-biased prediction of soil organic carbon and total nitrogen

529 with vis-NIR spectroscopy, as affected by soil moisture content and texture. Biosystems

530 engineering, 114(3), pp. 249-258.

531 Leslie, J.F., Summerell, B.A. (2006). The Fusarium Laboratory Manual. Blackwell Publishing, Ames,

532 IA

533 Magan, N., Hope, R., Colleate, A., \& Baxter, E. S. (2002). Relationship Between Growth and

534 Mycotoxin Production by Fusarium species, Biocides and Environment. European Journal of Plant

535 Pathology, 108(7), pp. 685-690.

536 Martens, H. and Naes, T. (1989). Assessment, validation and choice of calibration 537 method. Multivariate calibration, pp. 237-266

538 Milus, E.A., Kristensen, K., \& Hovmøller, M.S. (2009). Evidence for increased aggressiveness in a

539 recent widespread strain of Puccinia striiformis f. $\mathrm{sp}$. tritici causing stripe rust of

540 wheat. Phytopathology, 99(1), 89-94.

541 Moshou, D., Bravo, C.,West, J.,Wahlen, S., McCartney, A., Ramon, H. (2004). Automatic detection

542 of 'yellow rust' in wheat using reflectance measurements and neural networks. Computers and

543 Electronics in Agriculture 44 (3), 173-188.

544 Mouazen, A.M., Anthonis, J., \& Ramon, H., (2005). An automatic depth control system for online

545 measurement of spatial variation in soil compaction, Part 4: improvement of compaction maps by

546 using a proportional integrative derivative depth controller. Biosystems Engineering, 90(4), pp. 409-

547418.

548 Moshou, D., Bravo, C., Oberti, R., West, J., Bodria, L., McCartney, A. and Ramon, H. (2005). Plant

549 disease detection based on data fusion of hyper-spectral and multi-spectral fluorescence imaging

550 using Kohonen maps. Real-Time Imaging, 11(2), pp.75-83.

551 Mouazen, A.M. (2006). Soil Survey Device. International publication published under the patent

552 cooperation treaty (PCT). World Intellectual Property Organization, International Bureau.

553 International Publication Number: WO2006/015463; PCT/BE2005/000129; IPC: G01N21/00;

554 G01N21/00.

555 Oberti, R., Marchi, M., Tirelli, P., Calcante, A., Iriti, M., \& Borghese, A.N. (2014). Automatic 556 detection of powdery mildew on grapevine leaves by image analysis: Optimal view-angle range to 557 increase the sensitivity. Computers and Electronics in Agriculture, 104, 1-8.

558 Oerke, E.C. and Steiner, U., 2010. Potential of digital thermography for disease control. In Precision

559 Crop Protection-the Challenge and Use of Heterogeneity (pp. 167-182). Springer Netherlands

560 Peteinatos, G.G., Korsaeth, A., Berge, T.W. and Gerhards, R. (2016). Using Optical Sensors to 561 Identify Water Deprivation, Nitrogen Shortage, Weed Presence and Fungal Infection in 562 Wheat. Agriculture, 6(2), p.24. 
563 Polder, G., Van Der Heijden, G.W.A.M., Waalwijk, C. and Young, I.T., 2005. Detection of Fusarium 564 in single wheat kernels using spectral imaging. Seed Science and Technology, 33(3), pp.655-668.

565 Roggo, Y., Duponchel, L., \& Huvenne, J.P. (2003). Comparison of supervised pattern recognition 566 methods with McNemar's statistical test: application to qualitative analysis of sugar beet by near567 infrared spectroscopy. Analytica Chimica Acta, 477(2), pp. 187-200.

568 Rossi V, Ravanetti A, Pattori E, Giosue S. (2001) Influence of temperature and humidity on the 569 infection of wheat spikes by some fungi causing fusarium head blight. J Plant Pathol, 83, pp. 189570198.

571 Rotter, B.A., Prelusky, D.B., Pestka, J.J. (1996). Toxicology of deoxynivalenol (vomitoxin). Journal 572 of Toxicology and Environmental Health, 48, pp. 1-34.

573 Saeys, W.; Mouazen, A.M.; Ramon, H. (2005). Potential for onsite and online analysis of pig manure 574 using visible and near infrared reflectance spectroscopy. Biosystems Engineering, 91(4), pp. 393-402.

575 Schmale, D.G., III, \& Bergstrom, G.C. (2003). Fusarium head blightin wheat. The Plant Health 576Instructor. http://dx.doi.org/10.1094/PHI-I-2003-0612-01.

577 Sentelhas, P.C., Pedro, M.J., \& Felicio, J.C. (1993). Effects of different conditions of irrigation and 578 crop density on microclimate and occurrence of spot blotch and powdery mildew. Bragantia, 52, pp. 57945-52.

580 Silver, W.L., Neff, J., McGroddy, M., Veldkamp, E., Keller, M. and Cosme, R., 2000. Effects of soil 581 texture on belowground carbon and nutrient storage in a lowland Amazonian forest 582 ecosystem. Ecosystems, 3(2), pp. 193-209.

583 Stokes D.T., Scott R.K., Sylvester-Bradley R. et al. (1997). An Integrated Approach to Nitrogen

584 Nutrition for Wheat. London, UK: Home-Grown Cereals Authority: Project Report No. 159.

585 Sutton, J.C. (1982). Epidemiology of wheat head blight and maize ear rot caused by Fusarium 586 graminearum. Canadian Journal of Plant Pathology, 4, 195.

587 Sylvester-Bradley R., Kindred D. (2009). Analysing nitrogen responses of cereals to prioritise routes 588 to the improvement of nitrogen use efficiency. Journal of Experimental Botany, 60, pp. 1939-51.

589 Vachaud, G., Passerat de Silans, A., Balabanis, P. and Vauclin, M., 1985. Temporal stability of 590 spatially measured soil water probability density function. Soil Science Society of America 591Journal , 49(4), pp. 822-828

592 West, J.S., Bravo, C., Oberti, R., Lemaire, D., Moshou, D. and McCartney, H.A. (2003). The potential 593 of optical canopy measurement for targeted control of field crop diseases. Annu. Rev. Phytopathol, 41, 594pp. 593-614.

595 Whetton R.L., Waine T.W. \& Mouazen, A.M. (2017a). Optimising configuration of a hyperspectral

596 imager for on-line field measurement of wheat canopy. Biosystems Engineering, 155, pp. 84-95.

597 Whetton, R.L., Waine, T.W. \& Mouazen, A.M. (2017b). Hyperspectral measurements of yellow rust 598 and fusarium in cereal crops: Part 1: Laboratory study, Biosystems Engineering, 166, pp. 101-115.

599 Wu, D., Feng, L., Zhang, C., \& He, Y., (2008). Early detection of Botrytis cinerea on eggplant leaves 600 based on visible and near-infrared spectroscopy. Transactions of the ASABE 51 (3), pp. 1133-1139. 
601 Xu X.M. (2003) Effects of environmental conditions on the development of fusarium ear blight. Eur J

602 Plant Pathol, 109. pp. 683-689.

603 Zadoks, J.C., Chang, T.T., \& Konzak C.F. (1974). A decimal code for the growth stages of cereals.

604 Weed Research, 14(6), pp. 415-421.

605 Zhang, H., Hu, H. and Zhang, H. (2016). Monitoring Methods of Crop Diseases and Pests Based on

606 Hyperspectral Technology. International Journal of Simulation--Systems, Science \&

607 Technology, 17(11), pp.2.1-2.5.

608 Zhao, J., Zhang, D., Huang, L., Zhang, Q., Liu, W. \& Yang, H. (2016).. Vertical features of yellow

609 rust infestation on winter wheat using hyperspectral imaging measurements. In Agro-Geoinformatics

610 (Agro-Geoinformatics), 2016 Fifth International Conference on (pp. 1-4). IEEE.

611 Zhou, B., Elazab, A., Bort, J., Vergara, O., Serret, M.D. \& Araus, J.L. (2015). Low-cost assessment of 612 wheat resistance to yellow rust through conventional RGB images. Computers and Electronics in 613 Agriculture, 116, pp. 20-29.

614

615

616

617

618

619

620

621

622

623

624

625

626

627

628

629

630

631

632

633

634 
636 Figure 1: Hyperspectral imagery system mounted on a metal frame attached to the side of a tractor, 637 ready for on-line canopy measurement.

638 Figure 2: On-line hyperspectral measurement lines and position of ground truth plots, collected at 639 five samples per ha, in the four fields. Fields 1 and 4 were validated at the same locations at two time 640 intervals.

641 Figure 3: A block diagram illustrating the different steps followed for diseases quantification and 642 mapping.

643 Figure 4: Example of photo interpretation based assessment of \% coverage of yellow rust and 644 fusarium head blight based on a 100-point grid.

645 Figure 5: Spectra of wheat canopy collected at early (booting) and late (milk) growth stages, 646 comparing on-line and non-mobile (off-line ground truth) spectra as: (-) late non-mobile (---) early 647 non-mobile (...) early on-line, and ( $\ldots$ - ) late on-line.

648 Figure 6: Spectra of barley canopy collected at anthesis growth stage, comparing between on-line (--)

649 and non-mobile (-) spectra

650 Figure 7: Scatter plots of on-line measured versus predicted \% coverage of yellow rust in wheat 651 infield with visual assessment (IVA)-based partial least squares regression (PLSR) model (a), IVA652 PLSR prediction of yellow rust in barley (b), photo interpretation assessment (PIA)-based PLSR 653 model prediction of fusarium head blight in wheat (c) and PIA-PLSR prediction fusarium head blight 654 in barley (d).

655 Figure 8: On-line measured fusarium maps in the four experimental fields; field 1 with wheat (a) (4 656 ha anthesis), field 2 with barley (b) (10 ha anthesis), field 3 with wheat (c) (12 ha Milk), and field 4 657 with wheat (d) (7 ha Milk). 
658 Figure 9: On-line measured yellow rust maps in the four experimental fields: (a and b) refer to maps 659 of early stage scans in field 1 with wheat (4 ha booting) and field 3 with wheat (12 ha booting), 660 respectively. Maps of late stage scans are shown by (c) for field 3 with wheat (12 ha Milk), (d) for 661 field 4 with wheat (7 ha Milk) (e) for field 1 with wheat (4 ha anthesis) and (f) field 2 with barley (10 662 ha anthesis).

663 Figure 10: Soil moisture content map measured with the on-line visible and near infrared 664 spectroscopy sensor (Mouazen, 2006) and RGB images of crop in field 4. 


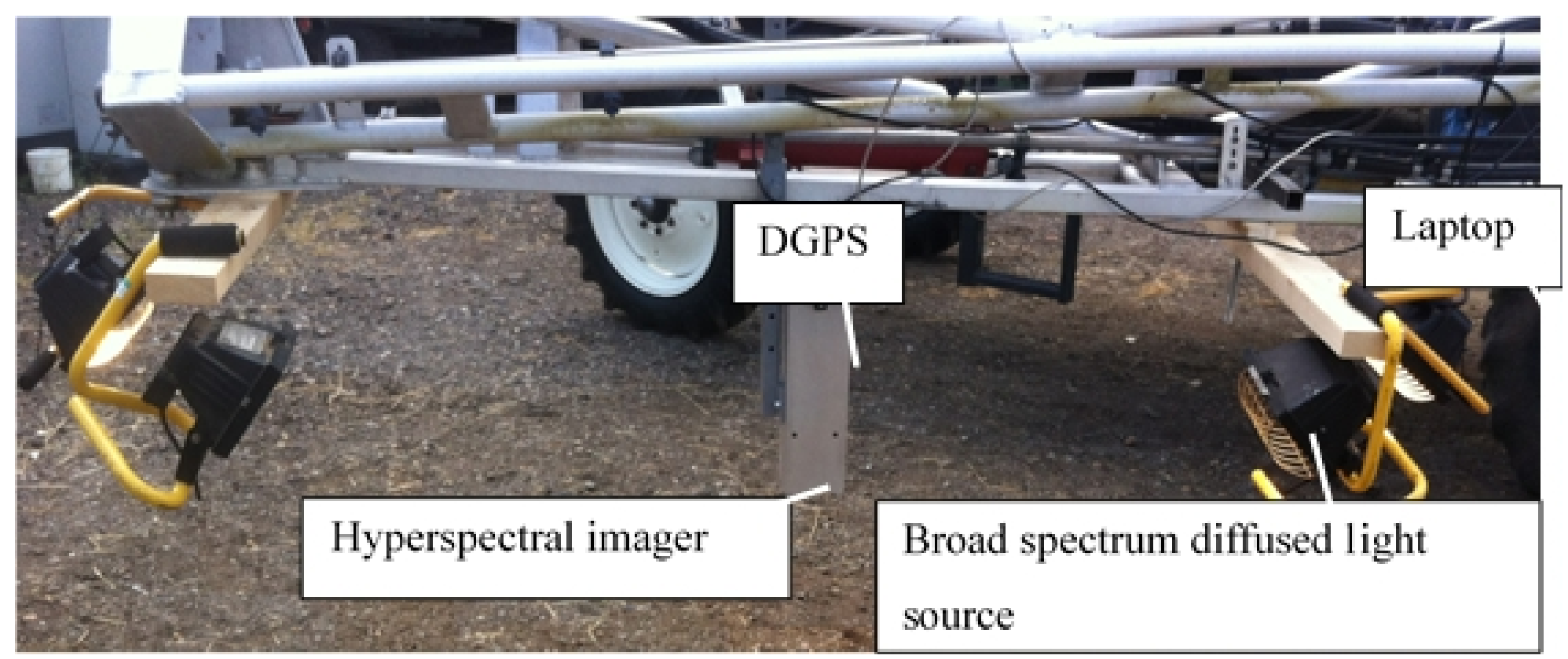




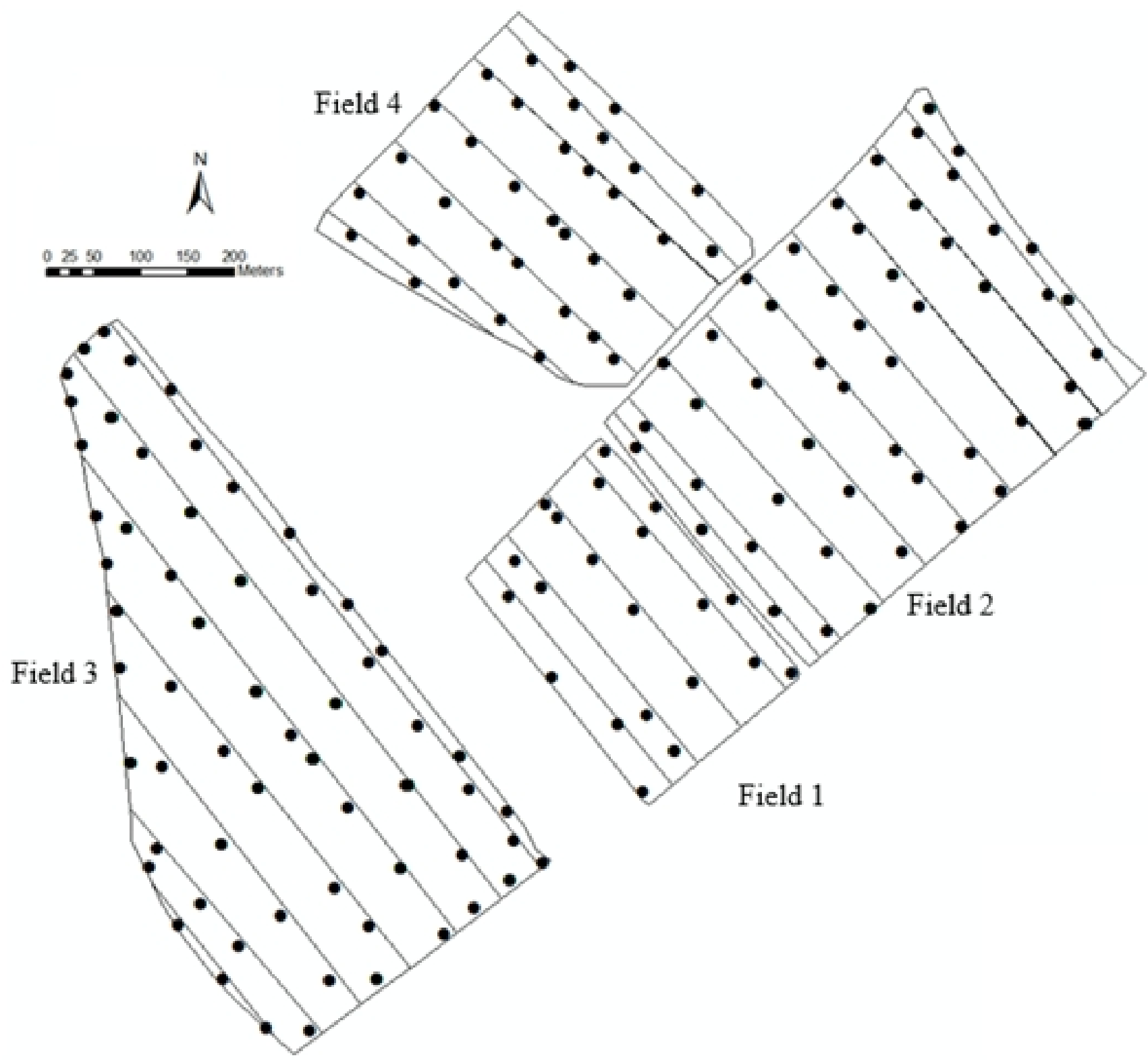




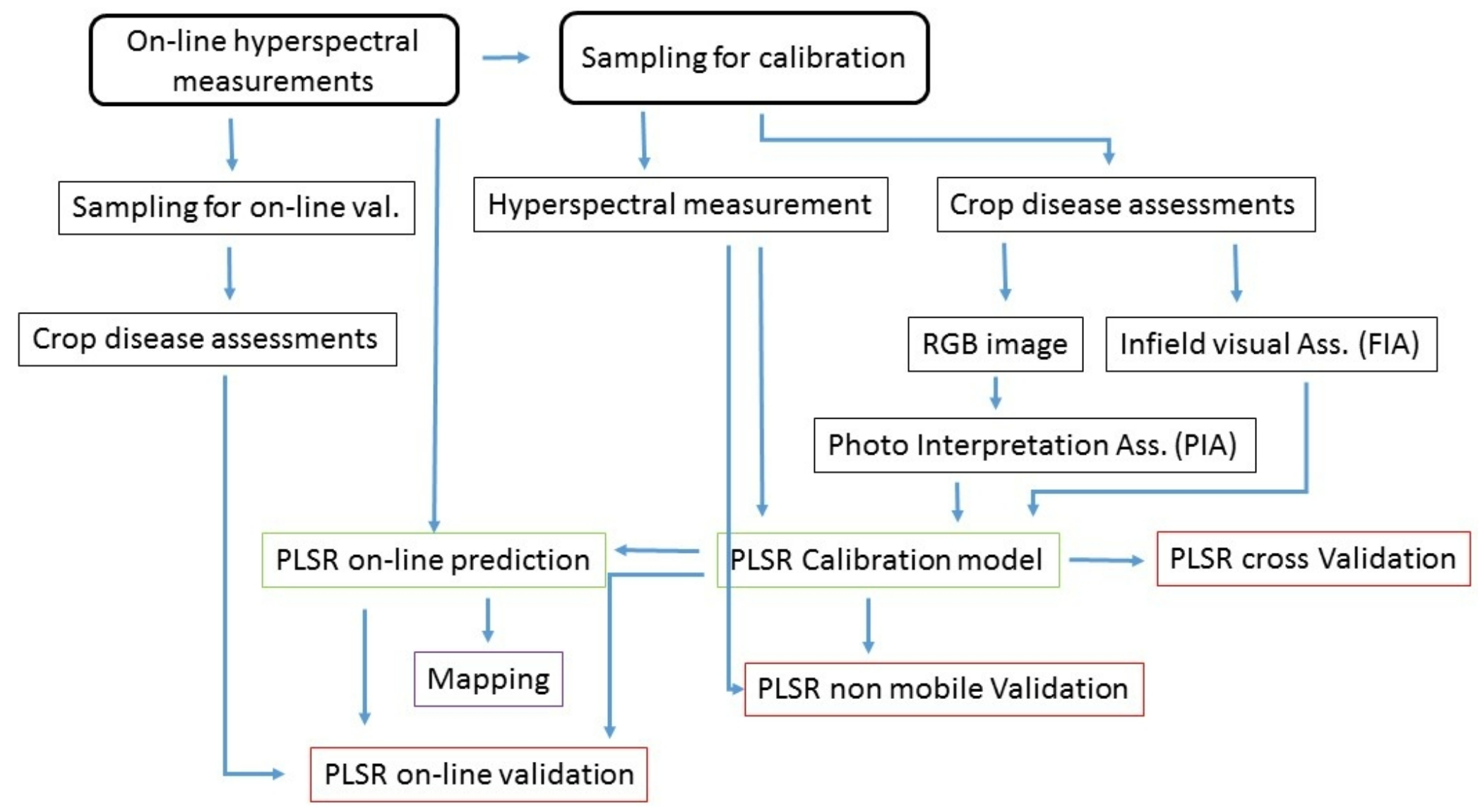




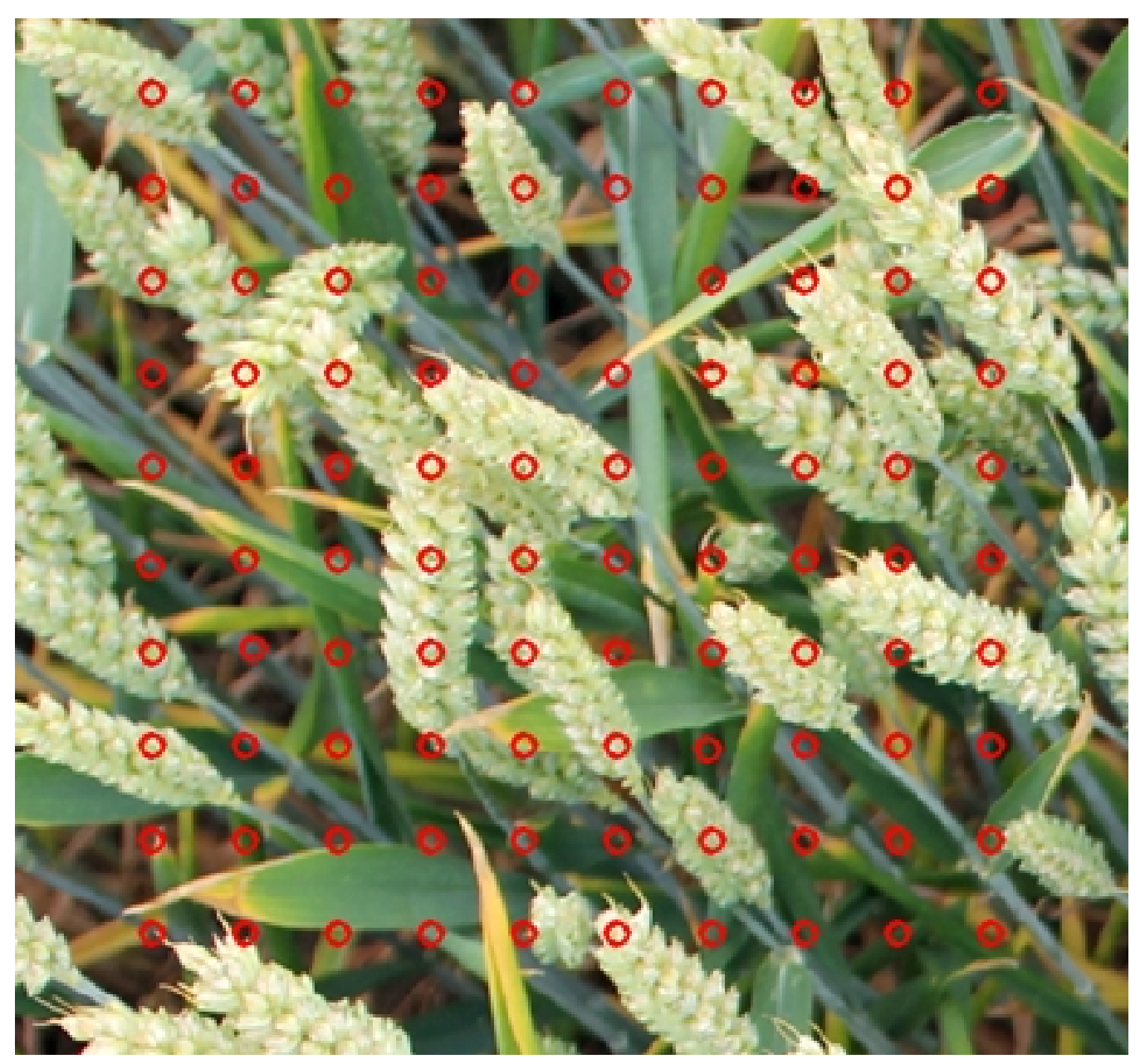




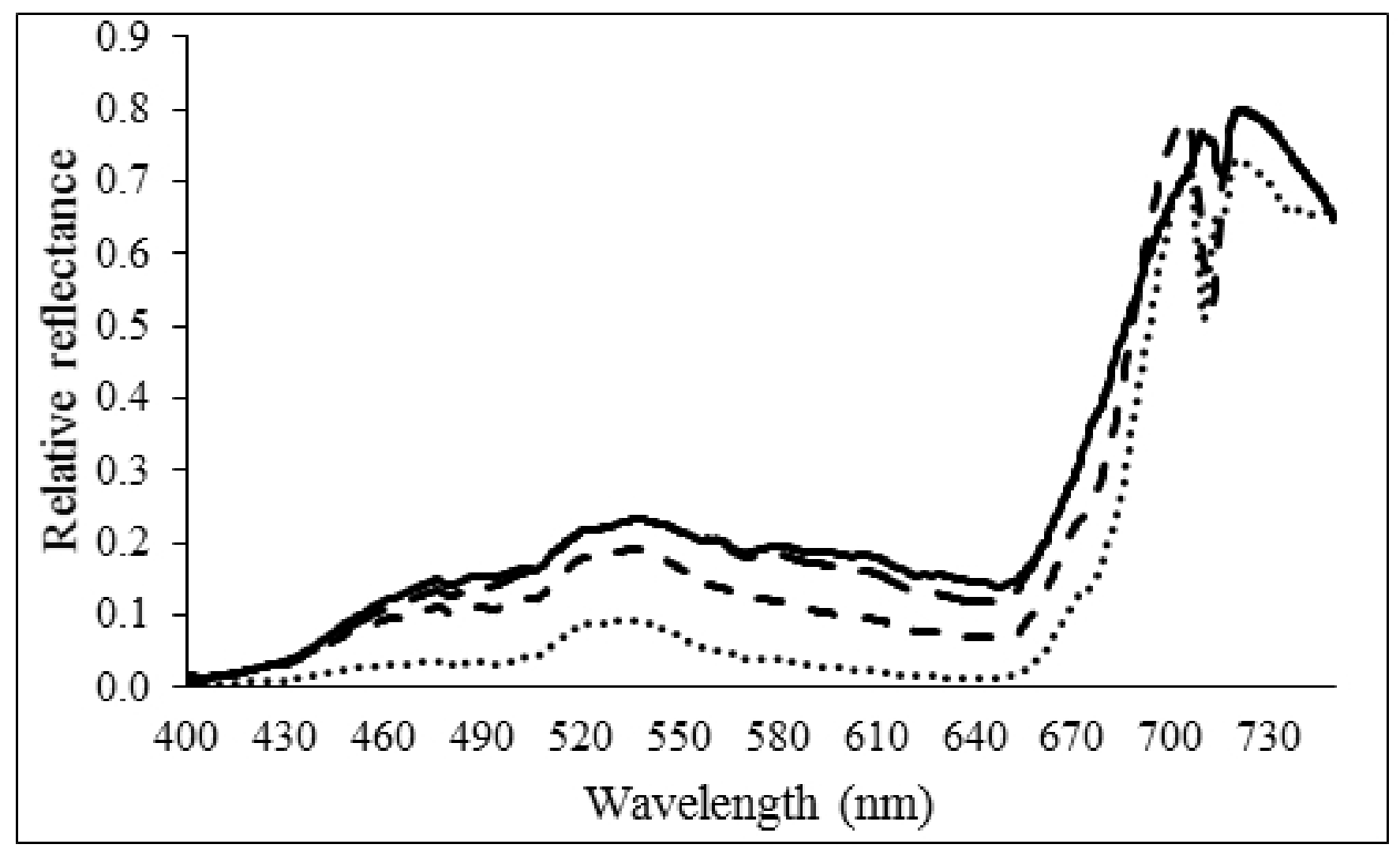




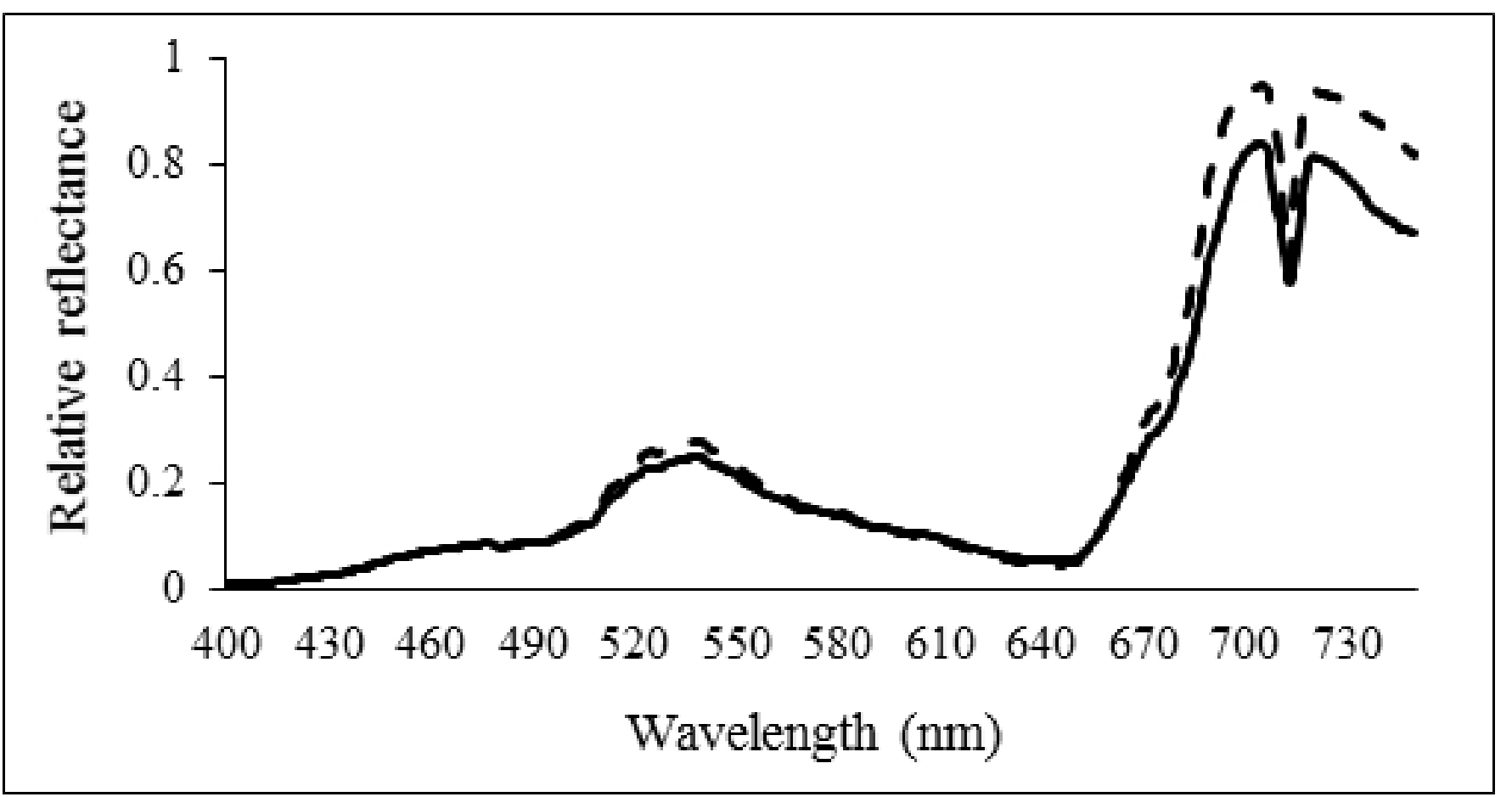




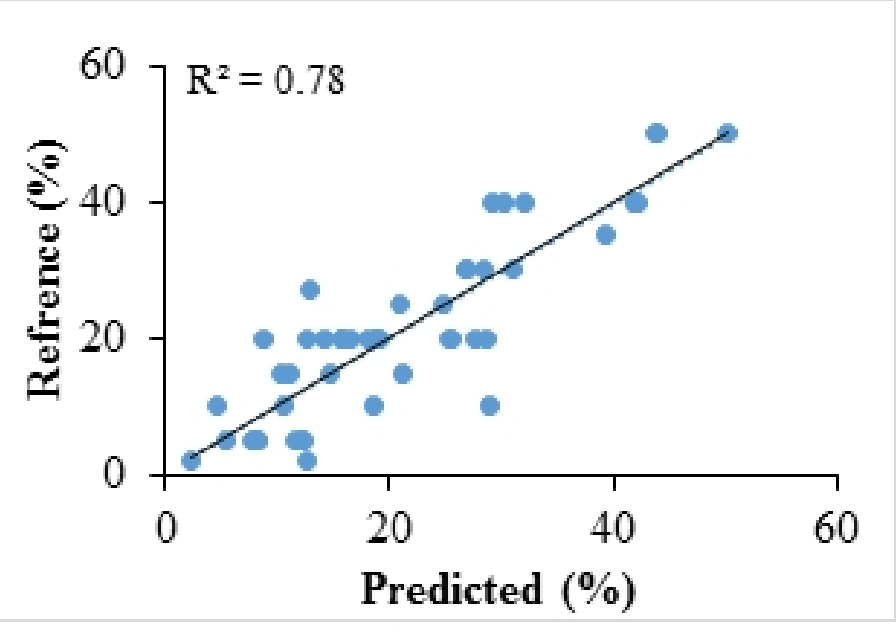

A

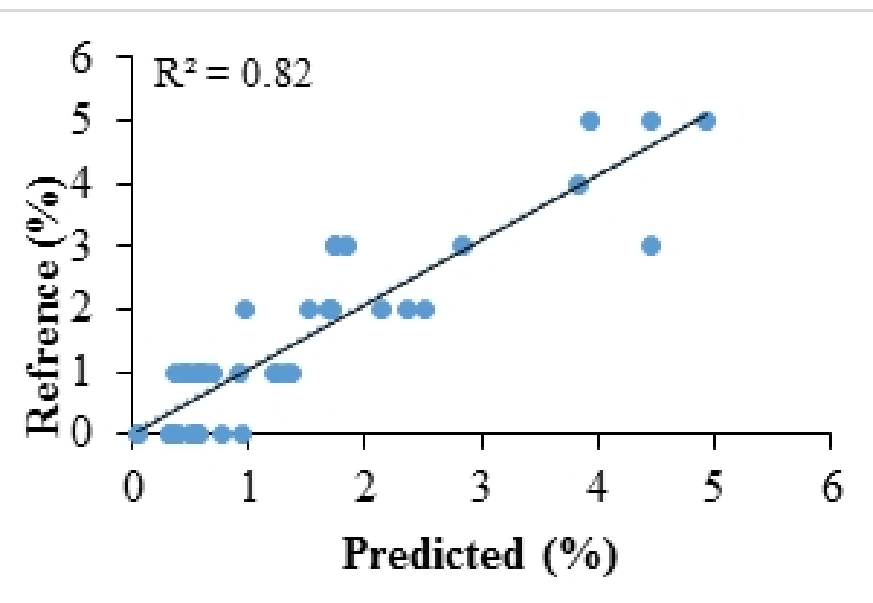

C

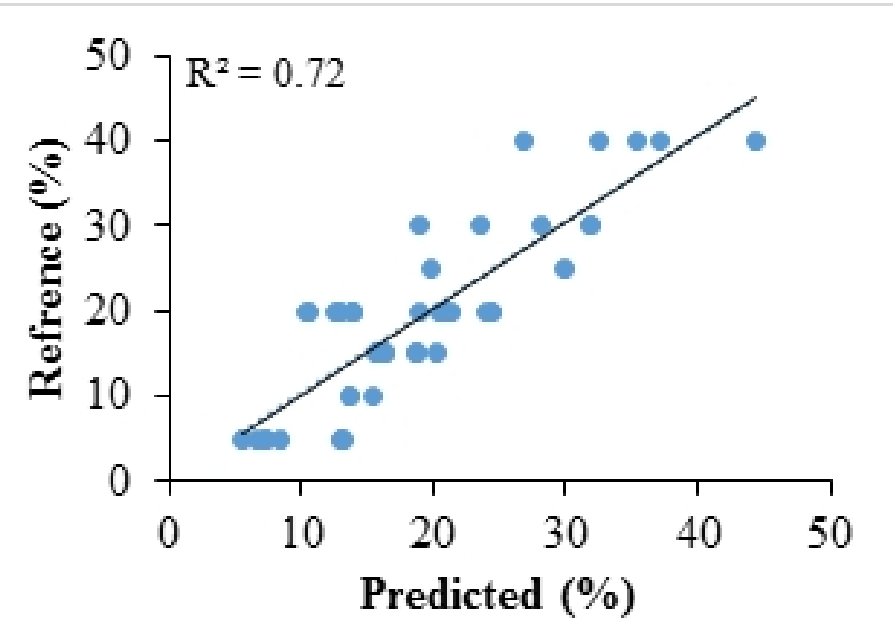

B

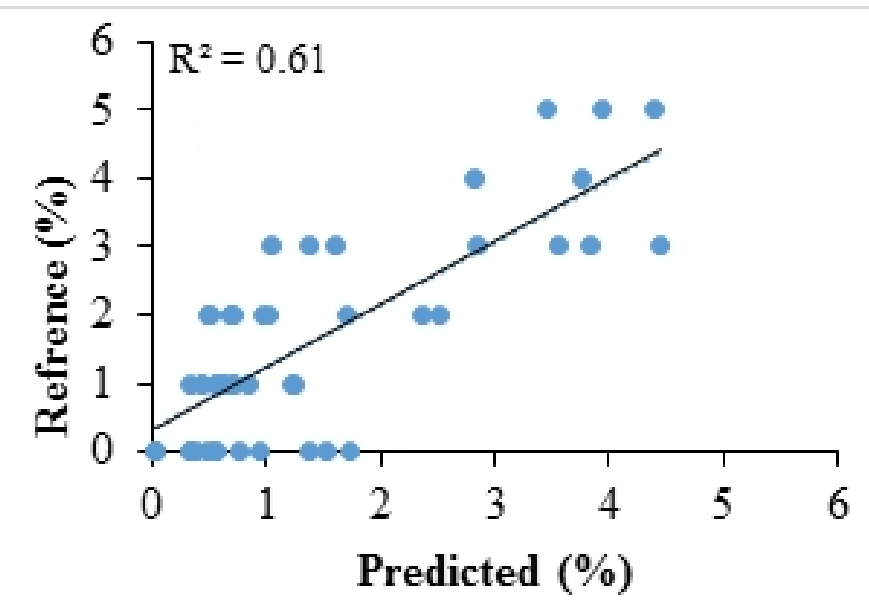

D 


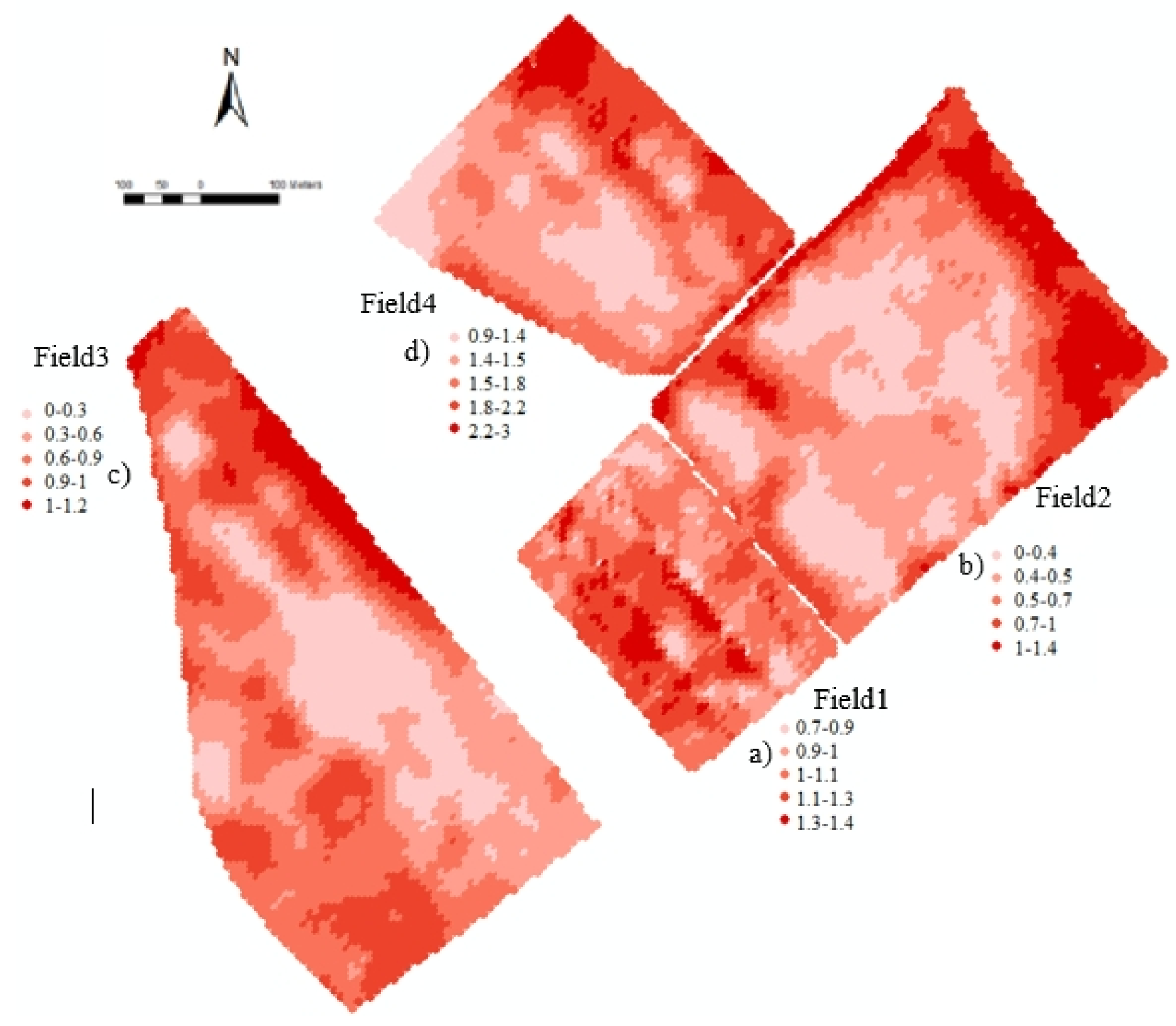




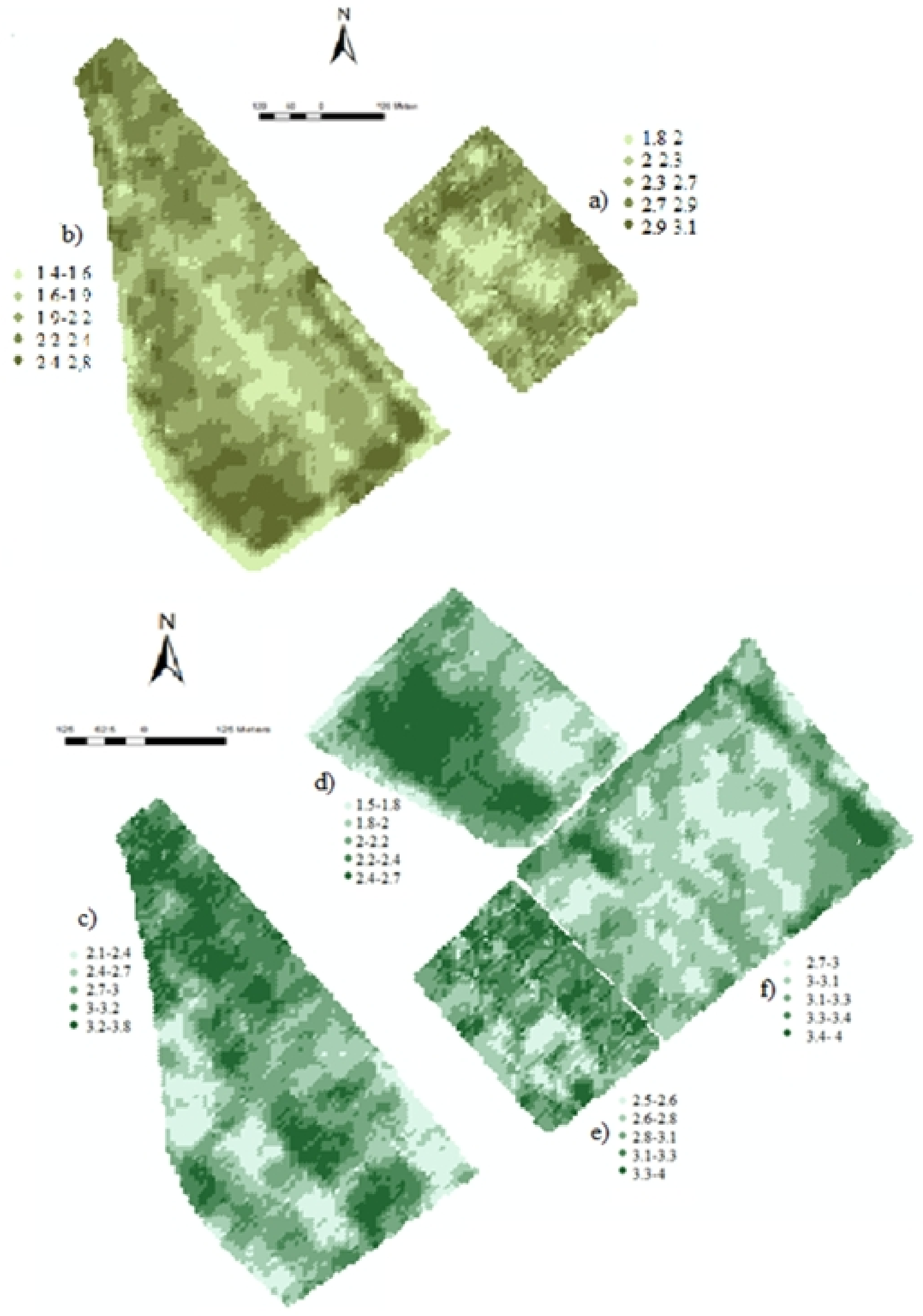




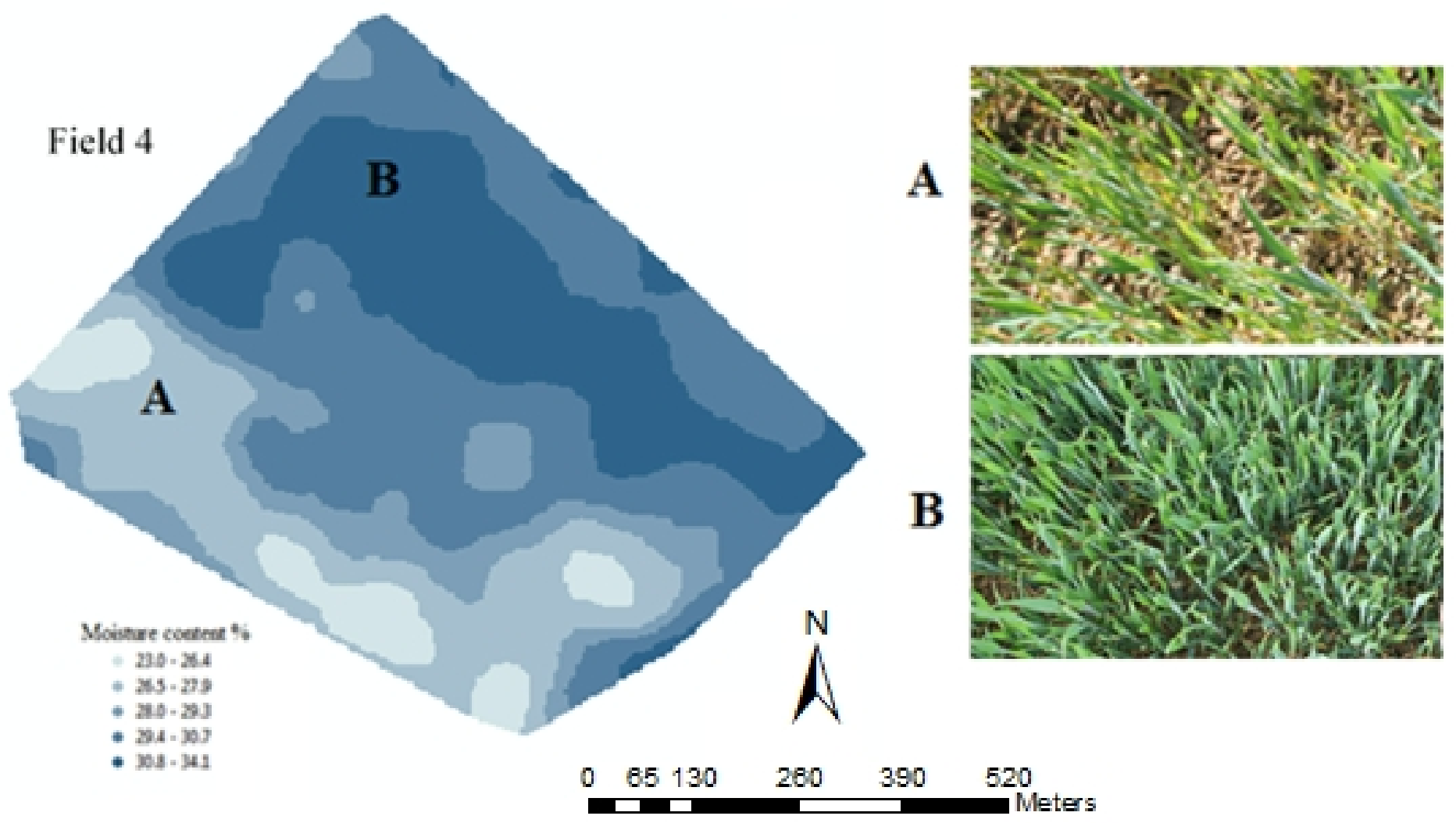


Table 1: Experimental fields, scanning time and growth stage identified according to the Zadok's scale (Zadoks et al., 1974). The soil type is presented for northern (N), southern (S) or eastern (E) and western (W) parts of a field.

\begin{tabular}{llllll}
\hline $\begin{array}{l}\text { Field } \\
\text { Number }\end{array}$ & $\begin{array}{l}\text { Field } \\
\text { area } \\
\text { (ha) }\end{array}$ & Crop & Soil type & Date of scanning & Crop stage \\
\hline 1 & 4 & Winter wheat & Sandy clay & $04 / 06 / 2015$ & Booting (43) \\
& & & $30 / 06 / 2015$ & Anthesis (61) \\
2 & 10 & Winter barley & N: Clay & $27 / 05 / 2015$ & Anthesis (61) \\
& & & S: Sandy clay & & \\
3 & 12 & Winter wheat & E: Clay & $22 / 05 / 2015$ & Booting (43) \\
& & & W: sandy clay loam & $01 / 07 / 2015$ & Milk (70) \\
4 & 7 & Winter wheat & E: clay loam & $01 / 07 / 2015$ & Milk (70) \\
& & W: sandy clay loam & & \\
\hline
\end{tabular}


Table 2: An example for the calculation of the \% coverage of yellow rust and fusarium based on a 100-point grid overlaid on an RGB image.

\begin{tabular}{lll}
\hline Object in centroid & Occurrence & Disease coverage \\
\hline Healthy leaf & 30 & 15 for yellow rust \\
Yellow rust leaf & 15 & \\
\hline Healthy ear & 20 & 3 for fusarium \\
Fusarium ear & 3 & \\
\hline Stem & 7 & NA \\
\hline Other (e.g., bare soil, & 25 & NA \\
senesced leaf) & & \\
\hline
\end{tabular}


Table 3: Statistical overview of samples used for the partial least squares regression (PLSR) analyses for the assessment of yellow rust in wheat.

\begin{tabular}{|c|c|c|c|c|c|c|}
\hline & \multicolumn{3}{|c|}{$\begin{array}{l}\text { Infield visual assessment (IVA) } \\
(\%)\end{array}$} & \multicolumn{3}{|c|}{$\begin{array}{l}\text { Photo interpretation assessment (PIA) } \\
(\%)\end{array}$} \\
\hline & $\begin{array}{l}\text { Cross- } \\
\text { val. }\end{array}$ & $\begin{array}{l}\text { Non- } \\
\text { mobile }\end{array}$ & On-line & $\begin{array}{l}\text { Cross- } \\
\text { val. }\end{array}$ & $\begin{array}{l}\text { Non- } \\
\text { mobile }\end{array}$ & On-line \\
\hline $\mathrm{Nr}$ & 188 & 47 & 47 & 188 & 47 & 47 \\
\hline Max & 90 & 65 & 50 & 60 & 65 & 50 \\
\hline Min & 0 & 2 & 2 & 0 & 2 & 2 \\
\hline Mean & 15 & 20 & 20 & 7 & 10 & 10 \\
\hline SD & 17 & 18 & 13.4 & 14 & 12 & 16 \\
\hline
\end{tabular}

SD is standard deviation 
Table 4: Statistical overview of samples used for the partial least squares regression (PLSR) analyses for the assessment of fusarium in wheat.

\begin{tabular}{lllllll}
\hline & \multicolumn{2}{l}{$\begin{array}{l}\text { Infield visual assessments (IVA) } \\
(\%)\end{array}$} & & \multicolumn{2}{l}{$\begin{array}{l}\text { Photo interpretation assessment } \\
\text { (PIA) (\%) }\end{array}$} \\
\cline { 2 - 7 } & Cross-val & Non-mobile & On-line & Cross-val & Non-mobile & On-line \\
\hline $\mathbf{N r}$ & 124 & 31 & 31 & 124 & 31 & 31 \\
Max & 5 & 3 & 5 & 3 & 2 & 3 \\
Min & 0 & 0 & 0 & 0 & 0 & 0 \\
Mean & 0.9 & 0.5 & 0.6 & 0.7 & 0.5 & 0.6 \\
SD & 1.7 & 0.9 & 1.4 & 1.3 & 0.7 & 1.4 \\
\hline
\end{tabular}

SD is standard deviation 
Table 5: Statistical overview of samples used for on-line validation of yellow rust and fusarium in barley.

\begin{tabular}{lllll}
\hline & Fusarium & \multicolumn{3}{c}{ Yellow rust } \\
\hline $\begin{array}{l}\text { Infield visual } \\
\text { assessments } \\
\text { (IVA) (\%) }\end{array}$ & $\begin{array}{l}\text { Photo } \\
\text { interpretation } \\
\text { assessment } \\
\text { (PIA) (\%) }\end{array}$ & $\begin{array}{l}\text { Infield visual } \\
\text { assessments } \\
\text { (IVA) (\%) }\end{array}$ & $\begin{array}{l}\text { Photo } \\
\text { interpretation } \\
\text { assessment } \\
\text { (PIA) (\%) }\end{array}$ \\
\hline Nr & 50 & 50 & 50 & 50 \\
Max & 5 & 3 & 40 & 58 \\
Min & 2 & 1 & 0 & 3 \\
Mean & 2.6 & 1.9 & 5 & 20 \\
SD & 1.3 & 1.5 & 9 & 13 \\
\hline
\end{tabular}

SD is standard deviation 
Table 6: Classes of the ratio of prediction deviation (RPD) and their suitability for predicting yellow rust and fusarium in cereal crops, proposed by Whetton et al., (2017b).

\begin{tabular}{ll}
\hline RPD range & Class and prediction capability \\
\hline$<1$ & Poor model predictions - not useful. \\
$1-1.5$ & Possibility to discriminate between low and high values \\
$1.5-2.0$ & Moderate prediction capability \\
$2.0-2.5$ & Good prediction capability \\
$2.5-3.0$ & Very good prediction capability \\
$>3.0$ & Excellent prediction capability \\
\hline
\end{tabular}


Table 7: Summary of prediction performance of $\%$ coverage of yellow rust and fusarium in wheat in cross-validation and non-mobile independent validation. Models were developed with the five on-line scanning occasions in three wheat fields.

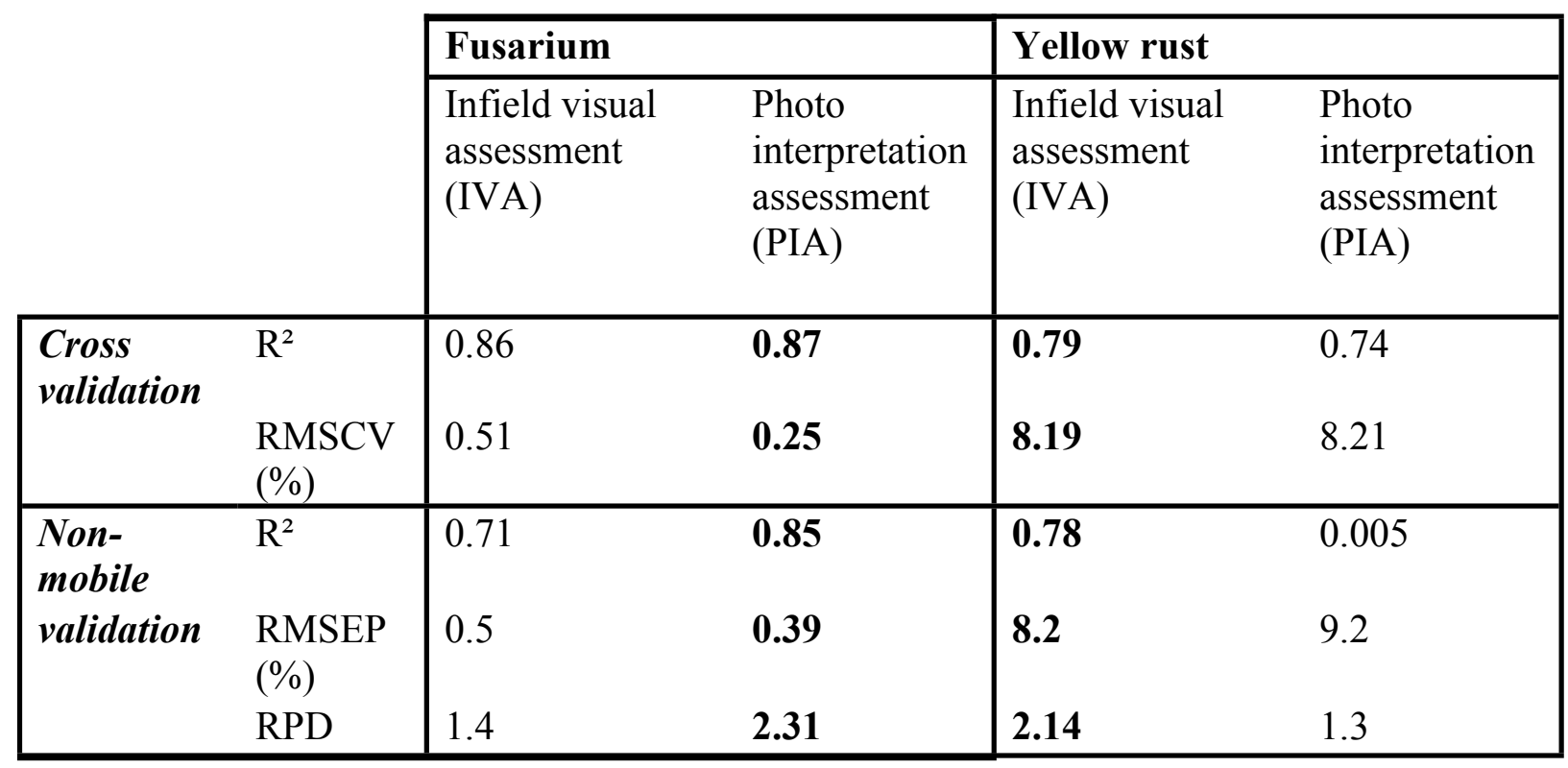

RMSECV is root mean square error of cross validation; RMSEP is root mean square error of prediction; RPD is ratio of prediction deviation = standard deviation / RMSEP 
Table 8: Summary of prediction performance of $\%$ coverage of yellow rust and fusarium in on-line validation using spectral data collected from three wheat fields and one barley field.

\begin{tabular}{|c|c|c|c|c|c|}
\hline & \multicolumn{2}{|l|}{ Fusarium } & \multicolumn{2}{|l|}{ Yellow rust } \\
\hline & & $\begin{array}{l}\text { Infield visual } \\
\text { assessment } \\
\text { (IVA) }\end{array}$ & $\begin{array}{l}\text { Photo } \\
\text { interpretation } \\
\text { assessment } \\
\text { (PIA) }\end{array}$ & $\begin{array}{l}\text { Infield visual } \\
\text { assessment } \\
\text { (IVA) }\end{array}$ & $\begin{array}{l}\text { Photo } \\
\text { interpretation } \\
\text { assessment } \\
\text { (PIA) }\end{array}$ \\
\hline \multirow{3}{*}{ Wheat } & $\mathrm{R}^{2}$ & 0.04 & 0.82 & 0.78 & 0.06 \\
\hline & $\begin{array}{l}\text { RMSEP } \\
(\%)\end{array}$ & 1.93 & 0.63 & 6.13 & 22.88 \\
\hline & RPD & 0.75 & 2.27 & 2.19 & 0.7 \\
\hline \multirow{3}{*}{ Barley } & $\mathrm{R}^{2}$ & 0.09 & 0.61 & 0.72 & 0.045 \\
\hline & $\begin{array}{l}\text { RMSEP } \\
(\%)\end{array}$ & 2.69 & 0.93 & 5.39 & 26.59 \\
\hline & RPD & 0.47 & 1.56 & 1.67 & 0.49 \\
\hline
\end{tabular}

RMSEP is root mean square error of prediction; RPD is ratio of prediction deviation $=$ standard deviation / RMSEP 
Table 9: Semi-variogram model parameters of each mapped disease in the four fields. The best fit was achieved with spherical models.

\begin{tabular}{|c|c|c|c|c|c|c|}
\hline & & \multicolumn{5}{|c|}{ Semi-variogram parameters } \\
\hline & & Nugget & Range & Sill & Proportion & Sum of square error \\
\hline \multirow{4}{*}{ 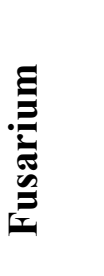 } & Field 1 & 0.12 & 86.39 & 0.71 & 5.51 & 2.95 \\
\hline & Field 2 & 0.37 & 99.46 & 0.83 & 1.70 & 1.41 \\
\hline & Field 3 & 0.11 & 97.02 & 0.89 & 8.02 & 3.32 \\
\hline & Field 4 & 0.04 & 75.62 & 0.77 & 18.98 & 0.00 \\
\hline \multirow{4}{*}{ 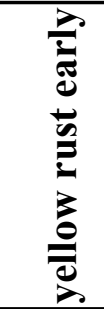 } & Field 1 & 0.001 & 77.75 & 0.002 & 1.001 & 3.383 \\
\hline & Field 2 & 0.001 & 68.1 & 0.003 & 2.002 & 8.029 \\
\hline & Field 3 & 0.0001 & 78.34 & 0.001 & 9.0009 & 2.56 \\
\hline & Field 4 & 0.02 & 76.63 & 0.043 & 1.173 & 0.0021 \\
\hline \multirow{4}{*}{ 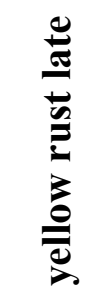 } & Field 1 & 0.01 & 77.75 & 0.022 & 1.212 & 2.11 \\
\hline & Field 2 & NA & NA & NA & NA & NA \\
\hline & Field 3 & 0.01 & 92.57 & 0.039 & 2.929 & 1.534 \\
\hline & Field 4 & NA & NA & NA & NA & NA \\
\hline
\end{tabular}

